\title{
Group Art Therapy, Aesthetic Experiences of Difference and Belonging
}

\author{
Sally Schofield ${ }^{1}$ \\ University of Manchester
}

\begin{abstract}
This paper comes from a qualitative doctoral study which explored the impact of group art therapy on people affected by Parkinson's. It specifically addresses the research question: How might participating in art therapy groups support wellbeing and better functioning for people affected by Parkinson's? Art therapy is not a widely applied therapeutic intervention for this client population. The study was undertaken at the Catalan Parkinson's Association which has a long-standing art therapy service integrated into the therapeutic rehabilitation programme. The language-based data gathered for analysis was from four focus group encounters with people affected by Parkinson's (who had directly experienced group art therapy), family members and professionals from the multidisciplinary team working alongside the art therapist. A thematic network analysis (Attride-Stirling, 2001) was undertaken producing six global themes in response to the research question: self-construction; material action; an aesthetic group movement; new perspectives; artwork as legacy; physical transformation as a relational aesthetic experience. I first describe how the research participants joined the study, the rationale for the focus groups and their composition; followed by a detailed exploration of the six themes, relating them to wider literature and a discussion of their implications for practice.
\end{abstract}

\section{Introduction}

This paper comes from a qualitative doctoral study which explored the impact of group art therapy on people affected by Parkinson's. It examines their experience of self through active engagement with art materials and the group environment in the space of group art therapy sessions. It further draws on the opinions of family caregivers and members of the multidisciplinary team, who have not directly experienced group art therapy, but have indirect experience being exposed to art therapy through either contact with the art therapist or the experience a person with Parkinson's has shared with them. I have specifically chosen to use the term Parkinson's instead of Parkinson's disease in an attempt to move away from thinking about the term as solely a medical pathology. However, in some instances I have used the full terminology to avoid confusion. The original study draws on three data-sets: 1) four focus groups; 2) ten individual interviews; 3) nine group art therapy session recordings. Each data-set addresses a specific research question which move from general to specific aspects of art therapy with this client group. This article is a response to the first research question: How might participating in art therapy groups support wellbeing and better functioning for people affected by Parkinson's? The rationale for taking this angle is that the findings, although derived from the focus group material, were pertinent across the datasets. I used thematic network analysis to

1 Correspondence concerning this article should be addressed to Dr. Sally Schofield. Email: sallyjschofield@gmail.com

Language and Psychoanalysis, 2019, 8 (1), 30-68.

http://dx.doi.org/10.7565/landp.v8i1.1591 
approach the material producing six global or main themes. The six themes were consolidated by triangulating the three datasets.

\section{Parkinson's and Art Therapy}

When asked to explain what Parkinson's is I would typically reiterate the definition from the Catalan Parkinson's Association's website. It describes Parkinson's as a neurodegenerative illness that is chronic and progressive. The condition affects the central nervous system, more specifically the cerebral structures which control and coordinate movements, and maintain muscle tone and posture. The presence of dopamine in these cerebral structures or 'substantia nigra' is vital for the regulation of movement, keeping it agile, effective and harmonious. A lack of dopamine in the substantia nigra leads to the main symptoms which are related to motor control: tremors, muscular rigidity, slow movement, postural anomalies, dragging feet or short steps, freezing and problems related to balance. (CPA, n.d., la Malaltia de Parkinson).

However, it does not adequately describe the day-to-day experience of Parkinson's for the individual affected. Parkinson's is a condition which affects more than 160,000 people in Spain, one in five of whom are under 50 (Peñas Domingo, 2015). The condition not only impacts the person physically but the diagnosis brings with it a number of socio-political and economic repercussions.

There are a number of studies in the field of nursing which explore the experience of living with Parkinson's disease (Habermann, 1996; Hermanns, 2013; Kang \& EllisHill, 2015). These studies emphasise that while the medical field treats Parkinson's symptoms, the condition affects the person as a whole. Hermanns (2013) highlights a changing sense of self in relation to living with Parkinson's, due to the perceived or real social stigma attached to having a chronic condition with visible symptoms. These imply a direct link between the symptom alleviation focus of the medical approach and the rupture people affected by Parkinson may experience with their sense of self. Kang \& Ellis-Hill (2015) argue for the need to consider the subjective experience of Parkinson's in order to help people affected adjust to their particular life changes.

The medication for Parkinson's has to be taken a number of times a day following a strict timetable and although it relieves motor symptoms for short periods, it has a number of side effects which, over time, can become serious. For example the group of dopamine agonists, most frequently administered to young people with early onset Parkinson's, are known to be associated with obsessive-compulsive behaviour (Peñas Domingo, 2015). Long term Levadopa treatment is frequently accompanied by the "on-off" phenomena, sudden fluctuations between "on" to "off" which incapacitate the patient from one moment to the next (Kulisevsky, 2004). A further side effect of the medication can be the development of dyskinesia, involuntary movements, appearing as the medication peaks (Kulisevsky, 2004). For all patients taking medication for Parkinson's there is a possibility of developing hallucinations and psychosis, but those who have developed some cognitive impairment are more prone to this (Kulisevsky, 2004).

Approaches to Parkinson's are changing today with more professional interest in ways people affected can self-manage their illness by, for example, altering their diet

Language and Psychoanalysis, 2019, 8 (1), 30-68. 
(Barichella et al., 2017; Shah \& Duda, 2015). However, there is conflicting evidence from such nonpharmacological approaches in that benefit tends only to show in patient-reported outcomes (Bloem et al., 2015); in practice the patient perceives the benefit and feels their personal needs are being addressed but this cannot be proved through conventional scientific measures.

Through the present study I have come to question how the experience of Parkinson's is constructed. I have found the field of critical psychology that works to offer a critique of psychology as a discipline, a useful literature base. One area of study is related to how ideas and theories from psychology have become mainstream and have been adopted by other academics and professionals to justify "their own programmes of normalisation and pathologisation" (Parker, 2007, p. 2). This works on the basis that the source of our problems are individualised and lie within us creating "forms of surveillance and self-regulation in everyday life" (Parker, 2007, p. 3). This perspective has helped me look with fresh eyes at the belief system which is underlying the experience of a condition such as Parkinson's and encouraged me to envisage alternative understandings.

A critique of most health research is that it does not account for embodied experiences of the condition it is studying, in other words tangible experiences of the body. Ellingson (2006) points out that most areas of health research "involve embodied actors caring for (or encouraging others to care for) their own and others' bodies in highly specific ways, yet there is little embodiment in the accounts of research" (p. 301). Ellingson (2006) theorises that the tradition of disembodied academic writing, using the passive voice, has perpetuated and been perpetuated by the western mindbody split; the mind being linked to fact or a rational proactive self, and the body as a producer of fictions, also being perceived as troublesome. This alignment has led to disembodied knowledge. Producing embodied accounts of research is a significant challenge, but the endeavour to use the body as a site for knowledge production puts the complexities of research in the foreground instead of producing "deceptively tidy accounts of research" (Ellingson, 2006, p. 299) typical in much medical and social science research.

There are few empirical studies on art therapy for people affected by Parkinson's. Strand and Waller (2010) used a narrative and discourse analytic approach in a pilot study of the benefit of individual art therapy over a 24 week period to people affected by Parkinson's and their caregivers. Their study touches on the impact of the medical discourse locating Parkinson's as a solely physical condition, considering this and the social stigma linked to psychological distress to be reasons why psychological support is seldom offered to, or sought by, those affected. They report art therapy as a satisfying approach for this client group as it "offers the potential creation of an active self in the therapy, as well as the reflective self, which more conventional talking therapies can offer" (p. 89), but they do not explore further the social and cultural implications of the Parkinson's diagnosis. They dismissed the possibility of group art therapy in their study on the perceived grounds of people with Parkinson's concerns over how their physical impairment might impact others. This view, however, could have the effect of reinforcing social isolation in this client group legitimating these fears. 
Elkis-Abuhoff, Goldblatt, Gaydos and Corrato (2013) carried out a mixed methods study to determine "whether patients diagnosed with Parkinson's disease would be able to experience a decrease in the somatic and emotional symptoms of the disease by engaging in the manipulation of clay" (p. 123). They involved caregivers and noncaregivers in the control group and discovered that the caregivers could also benefit from emotional support through art therapy. Although not explicitly acknowledged in this study, this supports the idea that Parkinson's is a socially and culturally embedded condition, not only affecting the individual; those closest to them may also be prone to mental health problems due to the social burdens of the caregiver role.

Hoffmann (2011) conducted a single-subject case study to examine the effects of art therapy on cognitive impairment associated with Parkinson's disease. There was a pre/post battery of tests and the client and his primary caregiver were asked to rate specific symptoms (depression, dementia and psychosis) weekly during the six-week intervention. While this study aimed at "strengthening the client's sense of selfidentity" (Hoffman, 2011, p. 5) by improving self-esteem and memory recall through art therapy directives, the study is embedded in an individualised treatment model and does not contemplate the wider social context.

Carr (2014) describes, beyond a condition itself, how the impact on patients of the diagnosis and treatment of chronic and life-threatening illnesses "disrupted their sense of self-identity" (p. 54). Her study using portraiture in art therapy supports the view of art therapy as being helpful in ameliorating this self-perception by working with the person as expert in their lived experience. There is a slightly broader literature base related to art therapy and cancer care (Bradt \& Goodill, 2013; Feen-Calligan, 2008; Puetz, Morley \& Herring, 2013; Wood, Molassiotis \& Payne, 2011), which could be relevant for art therapy with people affected by Parkinson's and other chronic conditions. However, there continues to be a predominant focus on symptom management through empirical studies. In a systematic review of this literature base Wood et al. (2011) did acknowledge that in the qualitative studies "a line of argument emerged [...] around the defence and development of selfhood; where cancer threatens to disrupt the survivor's identity, art therapy can be used to counter the challenge." (p. 143) The present study aims to both consider how the impact of the Parkinson's diagnosis might affect a person's sense of self and draw on the research participants' experience of art therapy to outline mechanisms of art therapy practice that might be of help to a person affected by Parkinson's.

The development of artistic skills after a diagnosis of Parkinson's has been explored in the field of neurology. The literature observes how the artistic production can increase and become more expressive and emotional after the diagnosis of Parkinson's (Canesi, Rusconi, Isaias \& Pezzoli, 2012; Chatterjee, Hamilton \& Amorapanth, 2006; Inzelberg, 2013; Kulisevsky, Pagonabarraga, Martinez-Corral, 2009) and raises the question as to whether this is due to the dopaminergic medication or an innate artistic ability which was dormant before the onset of Parkinson's. Chatterjee et al. (2006) noted the fluid movement and motor control during artmaking. Studies in this field do not however contemplate art therapy as a potential complementary therapy. Feen-Calligan (2008) suggests that medical professionals are not as knowledgeable about art therapy as they are about other disciplines, meaning potential participants are not referred, and notes the lack of studies describing the mechanisms of art therapy.

Language and Psychoanalysis, 2019, 8 (1), 30-68.

http://dx.doi.org/10.7565/landp.v8i1.1591 


\section{Method}

This site-specific case study took place at the Catalan Parkinson's Association (CPA). Art Therapy is recognised as beneficial for people with Parkinson's (Cossio, 2002; Elkis-Abuhoff et al., 2013; Strand \& Waller, 2011; Tingey, 2002, 2004; Wadeson, 2003;) however it is not a widely used therapeutic intervention for this client population. The research site was chosen for its singularity in having an art therapy service of long standing, integrated in the therapeutic rehabilitation programme for people with Parkinson's. The main inclusion principle for the study was that all participants had had experience of group art therapy as a treatment modality for people with Parkinson's at the CPA, through participating either in an art therapy group, or in multidisciplinary teamwork with art therapy, or through being a family caregiver of an art therapy group member.

\section{Table 1}

Summary of research methods and participant involvement

\begin{tabular}{|c|c|c|c|}
\hline Method & Participants & Sampling strategy & Data analysis $^{2}$ \\
\hline $\begin{array}{l}4 \text { focus group one-off } \\
\text { sessions, audio- } \\
\text { recorded and } \\
\text { transcribed: } \\
\text { 1. multidisciplinary } \\
\text { team members } \\
\text { 2. family members } \\
\text { 3. former art therapy } \\
\text { group members } \\
\text { 4. art therapists }\end{array}$ & $\begin{array}{l}9 \text { members of the } \\
\text { multidisciplinary } \\
\text { team ( } 1 \\
\text { representative each } \\
\text { discipline plus } 3 \\
\text { art therapists); } 6 \\
\text { former art therapy } \\
\text { group members; } 5 \\
\text { family }\end{array}$ & $\begin{array}{l}\text { Strategic and } \\
\text { convenience } \\
\text { sampling. }\end{array}$ & $\begin{array}{l}\text { In-depth thematic } \\
\text { network analysis. }\end{array}$ \\
\hline $\begin{array}{l}\text { Individual interviews } \\
\text { with artwork carried out } \\
\text { by author. Audio } \\
\text { recording and } \\
\text { transcription. }\end{array}$ & $\begin{array}{l}10 \text { current art } \\
\text { therapy group } \\
\text { members }\end{array}$ & $\begin{array}{l}\text { Convenience } \\
\text { sampling - current } \\
\text { art Therapy group } \\
\text { members were } \\
\text { offered an } \\
\text { interview }\end{array}$ & $\begin{array}{l}\text { Thematic analysis } \\
\text { of interviews. } \\
\text { Analysis of the } \\
\text { performative roles } \\
\text { of the artwork } \\
\text { present in the } \\
\text { interview. }\end{array}$ \\
\hline $\begin{array}{l}\text { Audio recordings and } \\
\text { transcription of } \\
\text { sessions and } \\
\text { photographic } \\
\text { documentation of } \\
\text { artwork produced in } \\
\text { each session }\end{array}$ & $\begin{array}{l}22 \text { current art } \\
\text { therapy group } \\
\text { members }\end{array}$ & $\begin{array}{l}\text { Convenience } \\
\text { sampling - all } \\
\text { current art therapy } \\
\text { group members } \\
\text { were invited to } \\
\text { participate. }\end{array}$ & $\begin{array}{l}\text { Thematic analysis } \\
\text { of the verbal } \\
\text { content. Discourse } \\
\text { analysis of the } \\
\text { transitions between } \\
\text { speech and art- } \\
\text { making }\end{array}$ \\
\hline
\end{tabular}

\footnotetext{
${ }^{2}$ Researcher kept visual and written researcher diaries throughout the research process and made response art after each focus group session / individual interview / session recording as a reflective tool in the analytic process.

Language and Psychoanalysis, 2019, 8 (1), 30-68. 
The study had a total of 41 participants, 27 of whom were people affected by Parkinson's. Most of the participants were born and had lived in Cataluña throughout their lives. Despite this for some of them Catalan was not their first language. Four participants moved to Cataluña in adult life from another region of Spain, Peru, Venezuela, and Mexico. For these four Spanish was their first language. Data was collected in Spanish and Catalan, and the thesis was written in English. Translation between languages: spoken, visual and written, was central in the thesis and came to be considered a method in the analytic process (Schofield, 2018).

\section{Ethics}

Following the criteria of the Manchester University Research Governance and Integrity (UREC) the study proposal was presented to UREC as high-risk, given the involvement of what was classed as a 'vulnerable' population. Careful consideration was given to obtaining informed consent; protecting the anonymity of the research participants; minimising the disruption of the art therapy sessions and avoiding the study impinging on the art therapists' routine practice. Another important feature was ensuring the study could be of direct benefit to all involved during and after the research process.

Other ethical dilemmas related to the fact that I was researcher-near (Mannay, 2010) as I had formed part of the multidisciplinary team at the site for 10 years. ${ }^{3}$ It was therefore important to make sure the information I provided about the study and ways of approaching potential participants, avoided any form of coercion. There were disadvantages but also advantages to my position. Assuming a privileged knowledge as an insider could effectively "silence[s] the multifaceted nature of identities, lifestyles and perspectives" (Mannay, 2010, p. 92) of the population. On the other hand, my position as therapist and member of the multidisciplinary team who had worked closely with people with Parkinson's gave me a greater understanding of the site and access to a participant-pool that a person new to the field would not have. I also gave careful consideration to the power dynamics, aiming to deconstruct everyday naturalised power relations (Mattos, 2015). ${ }^{4}$

\section{Focus Groups}

The overall study involved three datasets (as indicated in Table 1), for the purpose of this paper I am going to present the results of the thematic network analysis which was based on the focus group material and verified through the triangulation with thematic analyses of the other two datasets. The present in-depth thematic analysis formed the basis of the results for the study. The original thesis develops on these themes presenting an analysis of the performative roles of the artwork in the individual interviews and an exploration of the effects of the art-making and artwork on the transitions that occur in art therapy sessions with the Parkinson's client group. These will be the topics of future papers.

3 Two art therapists joined the team and continued to run the art therapy service as I joined the PhD programme. This was a year before data collection took place. 4 For a more detailed discussion of these issues see Chapter 2 in Schofield (2018).

Language and Psychoanalysis, 2019, 8 (1), 30-68. 
The focus group method was specifically chosen with an aim of actively encouraging consensus through co-construction of meaning to enable a group perspective. More than a collection of individual viewpoints, each voice influences and appropriates the ideas of other participants, constructing a group narrative particular to that encounter. Foulkes (1975/1986) highlights the group conductor is highly influential in determining the group culture.

My position as focus group conductor was multifaceted. I was known by the research participants as an art therapist and less so as a researcher and these positions influenced the course of the dialogue. For example in the former patient group all the participants knew me as their art therapist. This will be the subject of another paper but coming from a feminist post-structuralist epistemological standpoint it is important to reflect on the position of the researcher (gender, class, race) and how this might influence the material being produced. Talwar (2010) "calls for an examination of identity and difference from a sociocultural perspective in art therapy theory and practice" (p. 11) arguing that social positions cannot be considered in isolation but are intersectional, bringing into the foreground issues of power and privilege related to race, class, gender and sexuality.

\section{Table 2}

Summary of focus group participation

\begin{tabular}{|c|c|c|c|}
\hline $\begin{array}{l}\text { Focus group } \\
\text { (FG) }\end{array}$ & $\begin{array}{l}\text { Participants } \\
\text { (pseudonyms) }\end{array}$ & Gender & Connection to Parkinson's \\
\hline $\begin{array}{l}\text { Professional team } \\
\text { (FG1) }\end{array}$ & $\begin{array}{l}\text { Alba } \\
\text { Alicia } \\
\text { Carmen } \\
\text { Inés } \\
\text { Tamara } \\
\text { Inma }\end{array}$ & $\begin{array}{l}\mathrm{F} \\
\mathrm{F} \\
\mathrm{F} \\
\mathrm{F} \\
\mathrm{F} \\
F\end{array}$ & $\begin{array}{l}\text { Physiotherapist } \\
\text { Speech therapist } \\
\text { Music therapist } \\
\text { Neuropsychologist } \\
\text { Social-worker } \\
\text { Psychologist (written response to } \\
\text { interview questions) }\end{array}$ \\
\hline $\begin{array}{l}\text { Family members } \\
\text { (FG2) }\end{array}$ & $\begin{array}{l}\text { Amelia } \\
\text { Mercè } \\
\text { Miquel } \\
\text { Maria Luz } \\
\text { Nuria } \\
\end{array}$ & $\begin{array}{l}\mathrm{F} \\
\mathrm{F} \\
\mathrm{M} \\
\mathrm{F} \\
\mathrm{F} \\
\end{array}$ & Spouse of person affected by Parkinson's \\
\hline $\begin{array}{l}\text { Former Patients } \\
\text { (FG3) }\end{array}$ & $\begin{array}{l}\text { Eduard* } \\
\text { Eric } \\
\text { Jorge } \\
\text { Martí } \\
\text { Oscar } \\
\text { Salvador }\end{array}$ & $\begin{array}{l}\mathrm{M} \\
\mathrm{M} \\
\mathrm{M} \\
\mathrm{M} \\
\mathrm{M} \\
\mathrm{M}\end{array}$ & $\begin{array}{l}{ }^{*} \text { Current art therapy group member } \\
\text { Former art therapy group members }\end{array}$ \\
\hline
\end{tabular}

5 The research participants who were affected by Parkinson's were divided into two participant pools, the former art therapy group members and the current art therapy group members. The former art therapy group members participated in Language and Psychoanalysis, 2019, 8 (1), 30-68.

http://dx.doi.org/10.7565/landp.v8i1.1591 


\begin{tabular}{|l|l|l|l|}
\hline $\begin{array}{l}\text { Art therapists } \\
\text { FG(4) }\end{array}$ & Elisabet* & F & $\begin{array}{l}\text { *Art therapist who had collaborated with } \\
\text { the CPA before the study } \\
\text { Current art therapists working at the CPA }\end{array}$ \\
& $\begin{array}{l}\text { Marisol } \\
\text { Marianne }\end{array}$ & F & F
\end{tabular}

Table 2 summarises the distribution of participants in the four focus group meetings. There was no physical artwork involved, however a video of a former group participant's artwork, with a voice-over of his description of his experience, was shown in FG1, the multidisciplinary team, and FG2, the family caregivers. The video was originally made as an end of therapy review, a visual testimony for the client to keep and look back on after finishing therapy. I made these testimonies for each of the group members, this client's was the first to be completed and he was very satisfied with the result. He had already agreed to the use of the video for educational purposes and I asked for his permission to use it in this research as a visual aid in the focus groups FG1 and FG2.

The video functioned as a prompt for discussion for the research participants who did not have direct experience of art therapy. For the other two focus groups FG3, with former art therapy group members and FG4, with art therapists, this prompt was not considered appropriate given their personal experience with art therapy. In all the groups the idea of artwork and the creative process became a focus for discussion.

\section{Approach Analysis}

My position as artist-therapist-researcher brings a particular analytical lens to the material collected. The analytic process was undertaken paying careful attention to my researcher template (Goodley, 1999). This comprised a practice-based understanding of art therapy with this client group, an understanding of illness as being socially constructed (beyond its bio-medical definition) and a view of therapy as an intersubjective, relational process working with the experience of personal agency in order to illuminate "the distinctive structure of meanings that connects the different parts of the individual's world into an intelligible whole" (Atwood \& Stolorow, 1984, p. 5).

I approached the focus group material using thematic networks analysis (AttrideStirling, 2001). It is a flexible approach that can be applied to different conceptual frameworks and I found it particularly appropriate for the present research with its focus on group interaction. This form of analysis offers a structured way of exploring the negotiation of meaning by drawing on "connections between explicit statements and the implicit meaning in people's discourse" (p. 387). The aim was to explore how understandings of an idea or issue were constructed as opposed to reconciling different definitions.

The first part of analysis was broken down into three stages:

the focus group and the current members were present in the session recordings and were invited for individual interviews. Eduard was the only one who participated in all three of these activities.

Language and Psychoanalysis, 2019, 8 (1), 30-68.

http://dx.doi.org/10.7565/landp.v8i1.1591 
1. Coding the material - devising a coding framework (theoretical interests guided by the research question or salient issues in the text or both) and beginning to highlight sections of text according to this framework

2. Identifying themes - creating initial themes from the coded segments and refining them.

3. Constructing thematic networks - process of naming basic ideas in the coded segments to create sub-themes. The sub-themes were grouped to form what appeared to be the main assumptions of a broader claim in the data, a main theme. These main themes convey an overall idea interpreted in the transcript addressing the initial research question.

This is a simplified description of a back and forth messy process. I constantly referred back to the research question and the interview schedules in order to verify the relevance of the themes. I used NVivo to organise the transcripts in a database, reading each through in turn. I worked with the transcripts in the language spoken by the research participant (Spanish or Catalan) but created the themes in English as the thesis was to be written in English. Working across three languages meant I was constantly reflecting on the meaning being conveyed. My researcher template determined a particular interest in exploring how the focus group participants responded to the artistic component of group art therapy. However, I tried to keep the initial coding as inductive as possible, basing the codes on the content of the dialogue. I intended to form a rich description that is faithful to the overall content of the material I was analysing (Braun \& Clarke, 2006) as opposed to limiting it to specific aspects.

As coding progressed I looked beyond the semantic meaning of content to develop "latent or interpretative themes" (Braun \&Clarke, 2006, p. 84). This means I have interpreted underlying ideas and theorised on the themes in relation to concepts from both group art therapy (Skaife \& Huet, 1998; Waller, 1993), group analysis (Foulkes, 1975/1986; Nitsun, 1996, 2006), feminist critical theory (Butler 2006/1990; Haraway, 1988), and disability studies literature (Clare, 2001; Goodley, 1999, 2001, 2005, 2011; Goodley \& Runswick-Cole, 2012; Greenstein, 2013, 2014; Reeve, 2002). I was not only interested in the themes and how they developed across the groups, but also in the differences between them, the themes that were given space in some groups but not addressed in others. I used the images from my visual researcher diaries made at the time of the focus group meetings and the four images I made as creative responses to the focus group encounter to deepen and enhance my researcher reflexivity.

The main themes were:

1. Self-construction

2. Material action

3. An aesthetic group movement

4. New Perspectives

5. Artwork as legacy

6. Physical transformation as a relational aesthetic experience 


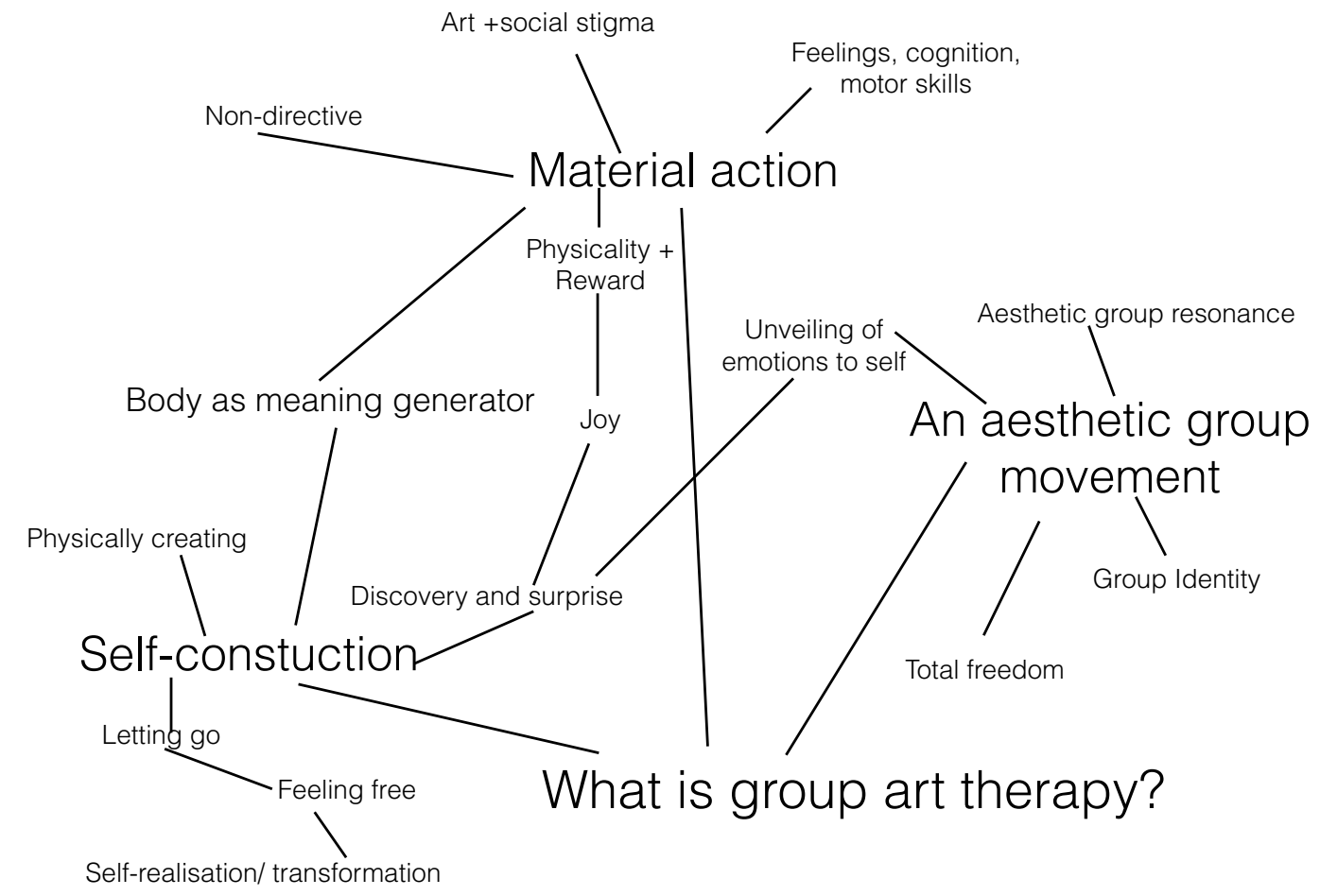

\section{Figure 1}

Thematic network 'What is group art therapy?'

Figure 1 is an example of a thematic network which I used as a visual aid, helping me organise the main themes and sub-themes at different levels and explore the connections between them. For example 'body [as a] meaning generator' I found as a sub-theme of 'self-construction' and of 'material action'. Post data analysis, I rendered hand-drawn thematic networks of the six main themes instead of representing them in digitally constructed diagrams. This process acted as a form of researcher-memoing. I am using the word render (inspired by $\mathrm{A} / \mathrm{r} /$ tography) to convey the transformation which takes place when ideas are translated into graphic representations or renderings. I intended to illustrate the contents of each main theme in a way that would be congruent with the rest of the project, however these images came to act as both visual reminders and help me develop my understanding of the themes.

$\mathrm{A} / \mathrm{r} /$ tography as a methodology is considered to be a line of enquiry "in the world through a process of art-making and writing" (Springgay, Irwin \& Kind, 2005, p. 899). This line of thought interrogates experience through art and words, not viewing them as different discourses reinterpreting each other, but asking what is enacted in the space of their relationship. By rendering the thematic networks graphically, I was introducing metaphor, colour, line and handwriting to my thematic network. These compositions helped me explore the construction of the global theme from an expressive, tactile perspective. 


\section{Results}

\section{Self-Construction}

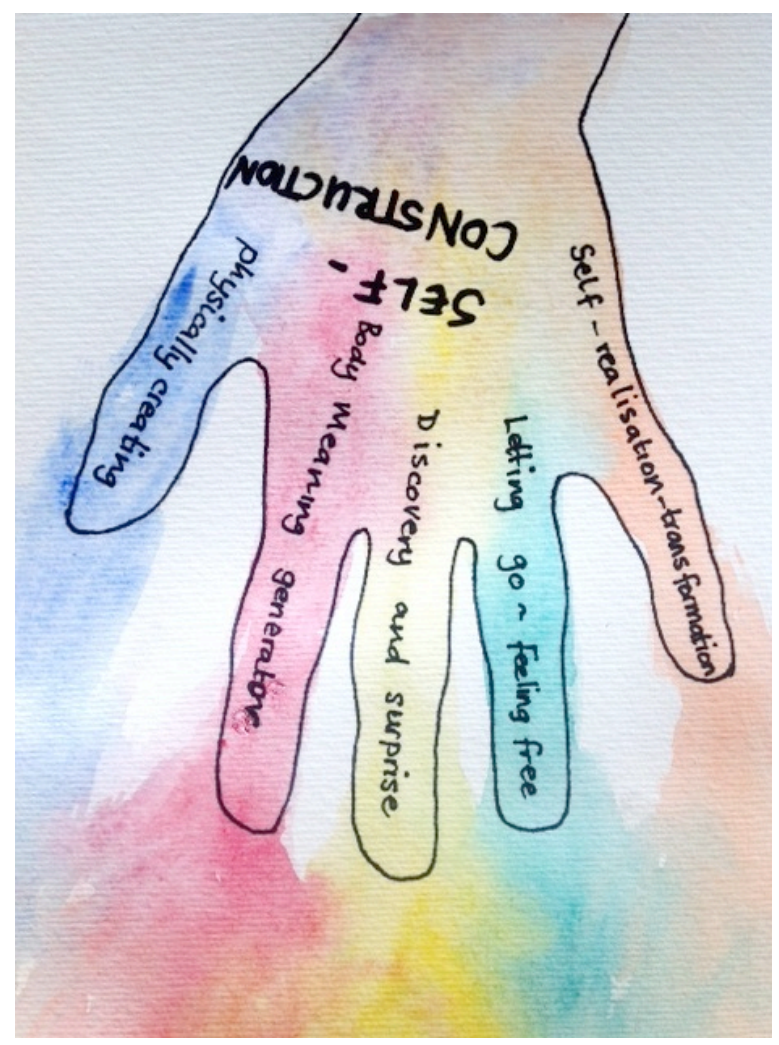

Figure 2

Thematic network 'self-construction'

The theme 'self-construction' (see Figure 2) alludes to a metaphorical rebuilding of the self, the person's sense of who they are, facilitated by their hands-on experience of physically creating and reflecting on the artwork, offering the possibility of increasing self-awareness and (re)discovering parts of themselves in a playful and satisfying way. This first theme also highlights the potential for self-transformation through the externalisation of issues and active engagement of physical manipulation allowing the person to challenge internalised beliefs.

This theme was composed of five sub-themes, the first being 'physically creating' (see thumb in Figure 2). FG1, with the professional team and FG4, the art therapists, put emphasis on art as an alternative mode of expression through physical construction. The professionals from the multidisciplinary team considered selfexpression (here understood as self-construction) through physically creating to compensate for a loss of the ability to use conventional verbal language to the same end. The discovery of a new, less conventional medium also leads to the discovery of new capacities. For example, in FG1, Tamara, a social worker, reflected on the expression of feelings: 
Tamara: Sometimes it is complicated expressing (.) in words or finding the right words because well, that's it, sometimes there aren't any words for those feelings (.) " $X$ " right? And so it is easier through art (.) well, to let these expressions flow, right? I mean, well, through the creation, well, of (.) figures or of artwork, than directly confronting yourself and saying what you are carrying inside, right?

In this extract there is a discourse that feelings are not adequately expressed in words, however physically creating allows them to flow. Tamara was a dominant voice in FG1 describing the task in art therapy in terms of the emotional, the physical and the social, suggesting these aspects are entangled.

All four focus groups linked self-construction to an element of discovery and surprise (see middle finger in Figure 2). Elisabet, FG4, builds on this discourse of art therapy triggering a hidden characteristic that the person may not have been aware of before:

Elisabet: This makes me think that we have had various patients that:: art therapy [laughs] has been the trigger that they discovered something, a talent that they thought that they didn't have, right? Or the fact that losing a more conventional language has made them (.) em:: discover a less conventional language.

Again the "talent" is not something an other teaches the person, but something that the action of using the materials spontaneously has facilitated. Similarly Carmen, the music therapist in FG1, also emphasised a return to the person through art and the possibility of rediscovering parts of themselves. Here self-construction is a process by which the person reconstructs the self in unexpected ways.

Carmen: Through well art they rediscover in themselves things that maybe they had put to one side and not even they themselves knew, right, so you find lots of surprises.

In the family members focus group, FG2, when asked to describe art therapy in their own words they described the challenge of letting go (see fourth sub-theme in Figure 2 ), which they saw as a desired state to facilitate creativity and the art therapeutic process. However some family members, for example Mercè, felt that their partners typically focused on the end result which involved control and frustration of expectations. Mercè, FG2, had been struggling to understand what art therapy was and how it might benefit her husband since he had expressed indifference about it. In the following exchange with Maria Luz she appropriates an understanding of art therapy that is constructed in this focus group:

Maria Luz: Art therapy I think is like:: (.) like a therapy (.) where you let go of emotions, not so much words, I mean like (.) through something that you do not know exactly what is going to come out, you express something you perhaps had hidden. In the case of Ignaci that is what he always stresses, that art therapy, has helped him (.) to get things out that he did not even want to admit to himself and that putting them on paper and seeing them after (.) "gosh, today I'm a little sad, no? I have done everything very dark" (.) and perhaps he didn't want to admit it at first [.....]

Mercè: Yes:: it's well, I think this is a another medium for communication (.) as they already find it difficult to communicate well, Alfredo has well, he's been

Language and Psychoanalysis, 2019, 8 (1), 30-68.

http://dx.doi.org/10.7565/landp.v8i1.1591 
pretty closed (.) and:: yes, the aiming for a result (.) so, that's wrong, I now see that, well (.) help him focus, well, that is not what is going to bring (.) satisfaction, but the ability to express, as he does with music (.) you have given me a good idea good because he is not perfect at music either.

Maria Luz uses a discourse of a psychological unconscious in self-construction, reinforcing the idea that the process of expressing affect (manifestation of bodily feelings and verbalisation of emotions) is neither readily comprehensible nor rational. Becoming aware of these manifestations therefore involves discovery and surprise. In the previous excerpt Mercè makes an important connection, as she comes to understand the aim of art therapy she associates the practice of art-making with something that is familiar for her husband, something he enjoys, which in turn could make the art-making process less threatening. In contrast to the other focus groups, the angle the former patients, FG3, take on self-construction is linked to freedom (see third finger Figure 2) and being sincere with themselves and the group. They emphasised the need for a safe other to facilitate self-construction, the other could be the artwork or the group. There was an emphasis on sharing and the role of the group as facilitator. The discussion developed around the importance of doing art in a group context, with the group widening the possibilities for art-making and how reciprocally the art-making helped reinforce a sense of group.

Jorge: Well in some way it lets you express yourself (.) um:: I don't know like:: when we are in group with more security, than no::

Salvador: Feel you are free.

Jorge: Yes yes feel you are free to express what (.) comes out of us at that moment (.) I think it contributes to:: that in some way well we empathise or (.) we show our (.) $/$

Salvador: Worries.

Jorge: Worries, our opinions without, without knowing we are (.) neither that we are owners of the truth nor that:: nor that anyone is going to judge us because:: because we are all there for that.

Salvador spontaneously fills in the gaps for Jorge, which Jorge incorporates into his narrative. Jorge reinforces an idea that certain conditions are needed to be able to express their worries and opinions freely, with "more security", with out being judged. These relate directly to desirable therapeutic boundaries which are promoted in group psychotherapy (Yalom \& Leszcz, 2005) in order to create a potential space (Winnicott, 1971/2005) in which the participants feel safe to explore.

Eduard: Art therapy is a ganzúa [picklock/skeleton key] (.) it is a kind of tin opener (.) that allows that which is closed with a key and we don't know how to open (.) to open (.) it is a-a trick (.) it is a pathway

Salvador: It opens your spirit

Eduard: Exactly

Jorge: I see it as a form of escaping (.) unconsciously from many things (.) and that you end up expressing them in (.) in something that could be a drawing or a-a painting (.) or something like that

Salvador: A figure, something, an object

Sally: What did you say about the spirit Salvador?

Salvador: That your spirit is freed

Language and Psychoanalysis, 2019, 8 (1), 30-68.

http://dx.doi.org/10.7565/landp.v8i1.1591 


\section{Sally: Uh-huh uh-hum}

Salvador: It opens up your spirit (.) it makes you be sincere with your companions (.) sin-sincere with them about your doubts, your fears, your shadows (.) and and esc- they are reflected in an object that can be a figure, or a drawing (.) a watercolour or a painting or as [xxxxx] of these

For the former art therapy group members feeling free was accompanied by a sense of art therapy being the key to unleash a part of themselves that is well hidden. Eduard compares art therapy to a ganzúa which translates as a tool to pick a lock in the absence of a key (RAE, 1992) or, as Eduard continues, a tin opener. The use of these metaphors stood out to me, on the one hand the idea of there being parts of Eduard hidden from himself and on the other the risk of the contents over-flowing, the way a tin needs to be opened carefully. The ambiguity of the metaphor holds a tension that in my experience can be extremely unsettling for the art therapy client, the desire to discover their 'true' feelings but the fear of facing internal chaos or being out of control, a turmoil the person has locked away. All the sub-themes described above (see the five fingers on the hand in figure 2) are linked, the process of making the art object takes an active part in the generation of meaning. Marisol, art therapist in FG4, made the distinction between art therapy and other physical therapies focusing on "motivation" over "recovery", suggesting the process of discovery through their body as something that has potential for self-realisation, as opposed to being a body that is faulty and needs rehabilitating. Marisol explains:

Marisol: Art therapy can lead them to discover (.) other abilities (.) that do not have anything to do with the the, the fact that the illness is eating away at them. [....] that the:: that the motivation comes from elsewhere that it is motivation and not recovery as could be in physio or speech therapy.

\section{Material Action}

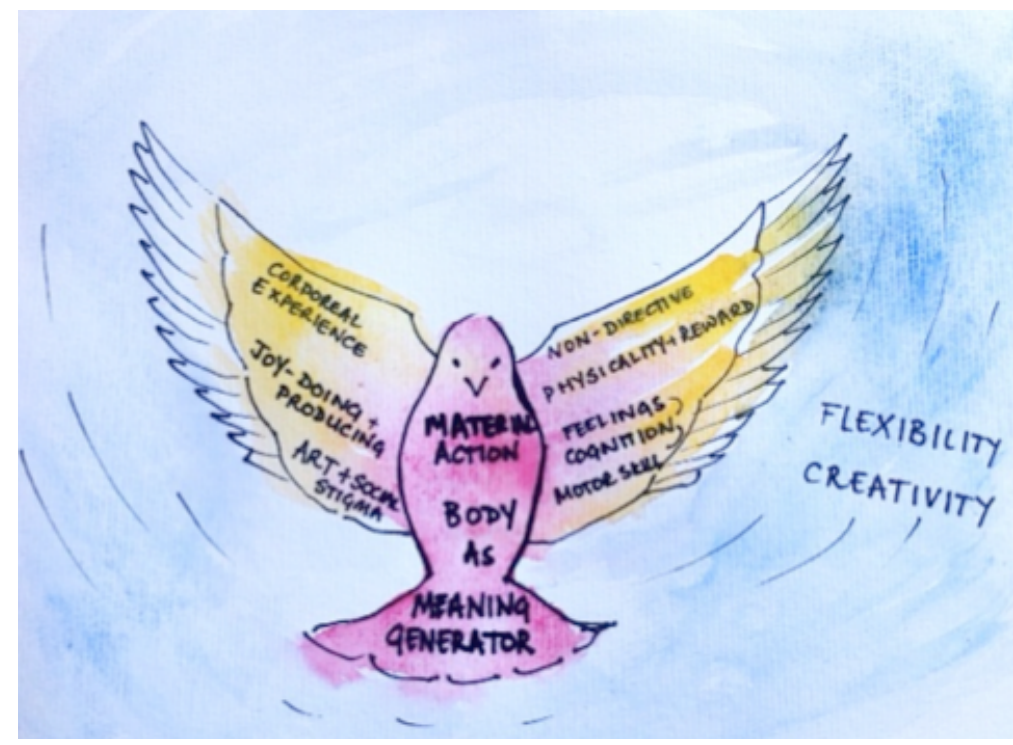

Figure 3

Thematic network 'material action'

Language and Psychoanalysis, 2019, 8 (1), 30-68.

http://dx.doi.org/10.7565/landp.v8i1.1591 
The second theme, 'material action' builds on an embodied engagement with the here and now in the art-making process enabling a tangible experience for self- reflection. In FG2, with the family members, Maria Luz was the youngest member by about 30 years. In the following excerpt she describes the physicality of the experience as becoming an effort as the illness progresses. The discourse of effort and reward infers that, handled correctly, this experience can have a positive impact on the person affected by Parkinson's helping them to adapt to uncertainty and a lack of control. In this example the unpredictability of drawing becomes exciting.

Marisol: As Parkinson's advances it [art therapy] transforms for them into a therapy that requires a:: (.) something physical and requires them to make an effort. This can motivate or demotivate them, it could put some people off or it could make some, well, think that it is not going to beat me and:: (.) I'm going to do the drawing I wanted to. It might be for others that it even helps them, as "I can't do something linear I'm going to let go and I'm going to do er the sketches/ marks that come out of me.

In FG1, the members from the professional team mentioned the positive impact the creative use of materials would have on fine motor skills and cognitive functions, but in the discussion this remained separate from the emphasis they put on the importance of the emotional response. The neuropsychologist, Inés, highlighted the potential for cognitive rehabilitation from the use of the art materials, directly linking creativity with flexibility:

Inés: Working with art mm on a cognitive level wakes up loads of functions (.) in fact from in fact creativity can be understood as in a more cognitive language as flexibility, right? Which in fact in the process of Parkinson's disease there are (.) there are many people who loose that flexibility to find other ways, right, to get to the same point and I think it is one of the key things that is worked with this through creativity, right, having tools and having to (.) plan as well as organise yourself er (.) focus attention right?

Inés further talks about the benefit of sensory stimulation for those who were suffering dementia, in more advanced stage of Parkinson's. The dominant discourse is psychological related to individual cognitive capacities. Inma, also a psychologist, on the other hand finds the physicality of working with materials as an experience which offers visual perspective and understanding.

Inma: [...] that the manual work, non-verbal enabled him to acquire a clearer view and take perspective about the process he was living with the illness.

Here a bridge is formed between the physical experience, the cognitive processes and the emotional. This could be understood in terms of the physical action of making offering a corporeal experience that can be translated into the construction of personal meaning for the maker, the body as meaning-generator.

Oscar: This idea is because:: Art Therapy has has has:: woken in me th- this instinct to do things. 
Oscar, a former patient, brought examples of his illustrated poetry to FG3. He periodically got it out and tried to share it with the focus group. At the time I was worried about us wandering from the task, however for him this was a result of art therapy. In 2010 he began with fortnightly individual art therapy sessions before joining an art therapy group. He was not dealing well with the diagnosis and was quite overwhelmed by his emotions. To help contain this and promote continuity I encouraged him to reflect and write something down between sessions. To this day he tells me that art therapy was how he discovered poetry; however it was poetry that discovered him. Over the eight years he wrote more than 500 illustrated poems that narrate his everyday experiences. Through the action of writing Oscar aesthetically transformed his experiences and they him.

In the FG4, the art therapists group, there was an emphasis on making connections between the use of materials and helping the maker to reflect on here and now experience. Marianne said:

Marianne: The umbilical cord between what we live and (.) experience and how we ourselves combine the materials.

In the following extract Elisabet mixes the different personal pronouns as she speaks: 'you' as a person choosing materials to create with your therapy; then 'you' as art therapist showing 'them' materials; 'we' as art therapists who limit the materials; provision of non-art materials related to a specific profession for 'them' and finally for 'him' to handle or manipulate. This movement conveys dilemmas I believe art therapists need to be aware of in their position of power in the therapeutic relationship. The aim is that the person is free to choose which materials they use but this is necessarily influenced by the choices of material the art therapist provides.

Elizabet: It depends on on:: the moment:: in which you are (.) you choose one [material] or you choose another, right? The more you have shown them and the more comfortable they feel, they themselves will have more options to choose from, right? (.) And I have been thinking, going over and over what we are leaving out (.) that we should not limit ourselves to showing them materials related to the artistic language. We can provide the opportunity that they work in art therapy with materials with which:: they feel more comfortable. If a mechanic arrives for therapy (.) why not have screws and rubber gloves and oil on the table if it is necessary? Things that make them feel comfortable because (.) it is close to what he had been, or if she happened to be a pastry chef, why not? (.) materials, flour and tools that remind she because in the end its about handling /manipulating.

The extract also leads me to think about an ideology of art as separate from the everyday. If art is to reflect social tendency surely art should be accessible to everyone, not just an elite few who are considered to be educated enough to understand. Across all four focus groups the discourse of "artistic" was linked to a minority with talent. Even the art therapists made a distinction between creating as a means of expression and an imaginary art-world as though the two were separate entities.

All the former art therapy group members spoke about stumbling upon art therapy by chance, it was not something they were looking for rather something that was Language and Psychoanalysis, 2019, 8 (1), 30-68. 
suggested to them. The members of the professional team considered this lack of awareness of art therapy as a discipline to be an obstacle for the service:

Tamara: It is the lack of awareness and fear, ok? More than anything because in our day-to-day, or anyone's, we are not used to valuing art so much, right? The idea is that you have to have a predisposition or you do not dare because it is what we already said right, you have this idea or label that "I'm not going to do it well, right?

However it is not only a lack of awareness of others it is the belief system embedded in the discourse of the professionals making the referrals. The ideal art therapy group member, beyond other criteria, is conveyed as needing an "emotional vein" or "sensitivity to express or connect" that, according to Tamara, not everyone has. In the underlying discourse here, artistic expression is something innate or a predisposition, not something that can be acquired. This limits both the profile of potential participants who would benefit from art therapy and of individuals who might become art therapists.

So to do art therapy (as a professional or a client) do you need an artistic predisposition, or simply need to be brave enough to "dare" yourself to do it? The discourse of art as an unfamiliar seemed to elicit fear. Here this is not just with reference to people affected by Parkinson's but society in general. In theory art therapy is understood but in practice it takes a lot of encouragement to try it. In FG3 the former patient, Salvador, talked about the reactions of new people joining their art therapy group:

Salvador: In a way when someone new comes (.) they always think with a different mind-set (.) that it is a little painting course or something like that. When they realize that it is free-expression of your feelings, expressing them through other medium other than talking (.) well the people see it as a little shocking. There are those who like it and those who don't.

Similar discourses continue framing art therapy as "shocking" and unexpected, in addition to the fact that it is considered to be not for everyone, but in this extract it is free-expression that people are said to find shocking. Elisabet, in the therapists group FG4, talked about the terms "ART" and "THERAPY" being deterrents. 


\section{An Aesthetic Group Movement}

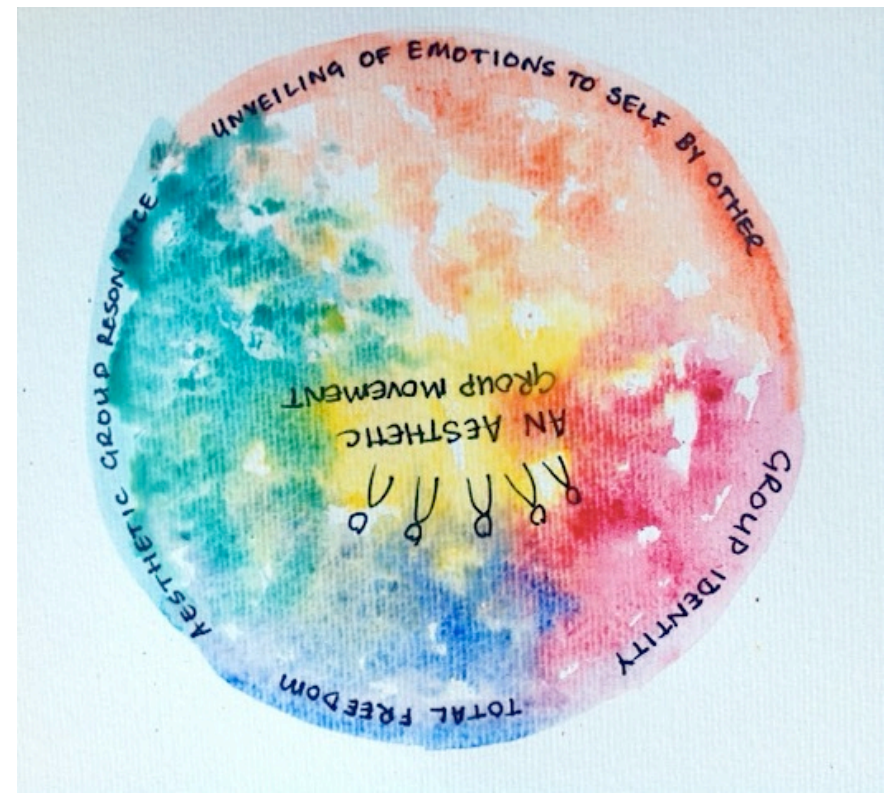

\section{Figure 4}

Thematic network an 'aesthetic group movement'

Enric: Being in a group (.) allowed me to do things in a less inhibited way (.) without instructions (.) er:: fundamentally if there was total freedom (.) and even more if at some point we do some a piece of work together (.) the famous murals (.) which at the beginning we did because it seemed that the group was frightened of expressing itself (.) however every time we did a mural together (.) coordinating (.) well I saw, saw and observed that everyone really enjoyed it (.) not because I was doing it but because we were all doing it together.

The third theme 'an aesthetic group movement' describes the importance of the group in the participant's experience of art therapy. In the above excerpt Enric, former art therapy group member, explained the freedom participants could feel as a combination of the non-directive approach to the art therapy space, and participation of the group as a whole. As he described, this group made a number of large murals together, an initiative that was begun by them and repeated periodically. Enric depicted the impulse of the group to create together as very important and motivating for him and the other former art therapy group members. 'Aesthetic group movement' describes the unique relational aspects of creating artwork together (individually in the same room or creating a group piece) and how this experience enhances group cohesion.

The group allowing a loss of inhibitions was repeated a number of times in the former patient group. Loss of inhibitions I had previously viewed as something undesirable, influenced by team discussions of a patient's socially inappropriate behaviour, considered to be a negative side effect of the dopaminergic drug treatment. The former group members' use of the term was clearly positive and drew my attention to

Language and Psychoanalysis, 2019, 8 (1), 30-68. 
me automatically medicalising the term. The loss of inhibitions in this focus group seemed to link to the desired sense of letting go that the family members and the art therapists highlighted; or as the professional team described the idea art allowing expression to flow in a way that verbal language does not.

The importance of the group in the art therapeutic intervention was recognised in all the focus group discussions. In FG3 with former patients Enric used the discourse of union and belonging, emphasising the members' ownership of the group space, attributing these characteristics to art therapy as an entity or whole experience in itself. This coincides with my experience as a group conductor in latter stages of groups as they became increasingly autonomous in their group culture. I often felt placed in the position of a privileged observer, sometimes to the point of playing such an insignificant role that I doubted the need for my presence.

Enric: One of the virtues of (.) in this case was precisely (.) the union (.) the typical thing that says that union gives strength in this case it was confirmed (.) yes the people felt that they formed part of a group (.) and whenever you form part of a group and you are more or less conscious of forming part (.) then it brings you many more benefits and many fruits [idiom] er:: than doing things on your own and without a leader or someone instructing you, the group forms the guidelines and I think in this case art therapy curiously offered these characteristics which made the group stronger.

Eduard, an art therapy group member, positions group interaction as less threatening than one-to-one interaction; using the example of talking with "the wife". Using a definite article with wife, in Spanish, could infer he was speaking about wives in general but it could also have been extended to the female population commenting on gender differences. The focus group was all male and from this extract, I wonder what difficult topics may have remained unspoken due to my position as a female art therapist/focus group conductor. Difficulties were absent from this focus group discussion as were any explicit negative experiences of groups.

Eduard: [....] a conversation for example with the wife, sometimes it is difficult to talk about certain topics (.) what you are suffering or what you are going through (.) Because it is difficult to speak with just one person (.) but then in the group (.) one says one thing, the other another and things start coming out more softly

In this instance translating to English felt particularly unsatisfactory, not fully conveying either the description in Spanish which conjures the idea of the speakers in the group not having control over the content of the dialogue - "things" came out of their own accord or the idea that Eduard does not feel under scrutiny in the group.

The multidisciplinary team focus group FG1 also emphasised the group as central to the art therapy experience, bringing the individuals "out of themselves", allowing the expression of worries and fears, both through the act of creating and verbally sharing difficult experiences. Inés explains:

Inés: 'Doing group therapy one starts and they start motivating each other and they see that they can do it and that it starts coming out and they get inspired (.) and they start adding colour and the start explaining and as well they start bringing out (.) their internal self and the worries and fears, right?"

Language and Psychoanalysis, 2019, 8 (1), 30-68.

http://dx.doi.org/10.7565/landp.v8i1.1591 
In the family caregiver focus group (FG2) however, they put the role of the "teacher" or professional in the foreground as a force of power which has the ability to see inside the art therapy group members, in a way that is denied to family members. Nuria, for example does not consider art therapy or the creative-act as having a positive effect on her husband, in her view the group depends on the all-seeing eye of the professional.

Nuria: "And also expressing emotions I think, that, in our case is the:: the most positive (.) that he expresses his emotions, because at least, the teachers, always say to him what he expresses and a::always /

Amelia: Of course, but that he has to learn, right? It could be in person that it is more /

Nuria: He doesn't know, he doesn't draw, he doesn't like it I

Amelia: No but:: knowing how to communicate.

Nuria: But as they tell him he communicates emotions. He always talks to me about the word emotions, to mel

Maria Luz: That's good.

Sally: Uh hum.

Nuria: I mean that, as a preference or to have a good time or at home, no:: no::

Group: (laughter)

Nuria: / No no no no because no, thinking about drawing makes him feel bad, he has never liked it. And at home he does not distract himself drawing or anything.

Sally: No. However in the session he does feel, right? Well that:: /

Nuria: (switches to Spanish) It is the only place, the group, where the group is they express, and perhaps they do it to, even if it is due to the praise of the teacher (.) who knows, right? their:: what they think inside.

In this extract Nuria's repeated "no" shows a strong resistance to the value of the artistic or creative components of art therapy. It is as if the art therapist/ teacher is creating the connection between art-making and emotional response. Amelia and Maria Luz try to encourage a more flexible outlook, Amelia refers to the possibility of "learning" how to express, implying it is not something innate and Maria Luz gives agency back to Nuria's husband "it's good" that he talks about emotions. When Nuria continues to insist that he does not draw through preference the group laughs, introducing humour, serving to alleviate the tension of Nuria's fixed viewpoint. I also colluded with Amelia and Maria Luz attempting to bring Nuria back to a positive experience of art therapy sessions. Here Nuria changes language (literally Catalan to Spanish) to say that the group sessions are the only place they (plural, not just her husband) DO express.

The belief that thoughts and feelings need to be unveiled and expressed in order to support well-being and better functioning for this client group prevailed in all the focus groups. Also, the power to achieve this was placed in an other (the family assuming it to be the work of the therapist; the multidisciplinary team constructing the artwork as a revealing other and the former art therapy group members making the group itself the powerful other). In all instances the individual alone is constructed as not capable of understanding him or herself alone. This is related to the nuances of the reflexive verbs in their translation from Spanish/ Catalan to English as something being done to the subject, but for this very reason it is important to highlight.

Language and Psychoanalysis, 2019, 8 (1), 30-68.

http://dx.doi.org/10.7565/landp.v8i1.1591 


\section{New Perspectives}

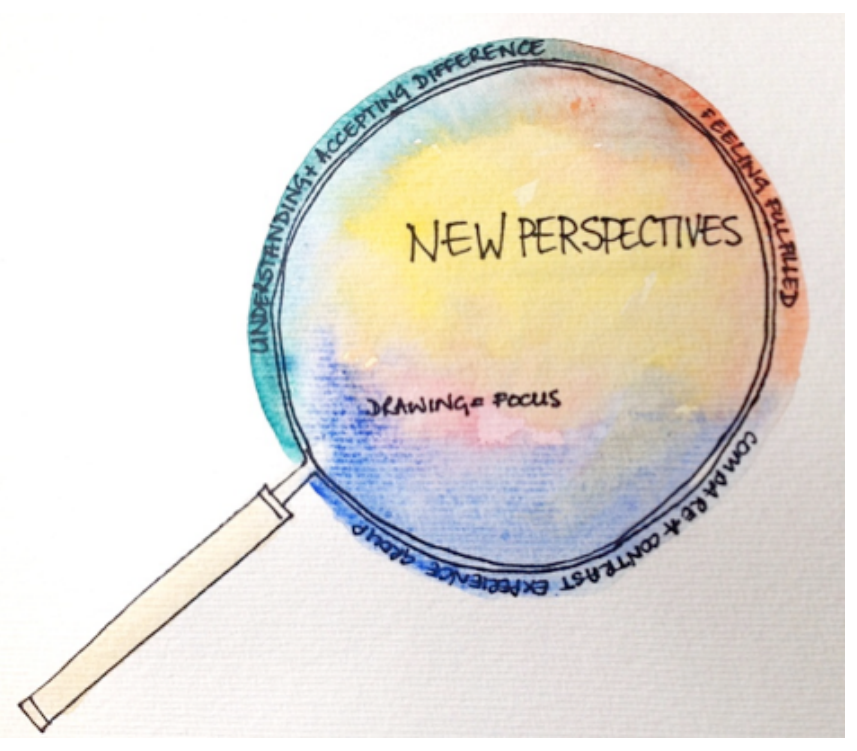

\section{Figure 5}

Thematic network 'new perspectives'

There were a number of comments in the four focus groups that related to seeing a situation from 'new perspectives', theme four, be that the Parkinson's condition, their outlook on life or a personal situation. The art-making in art therapy offers the opportunity for participants to use an alternative form of expression, a material medium which gives the issue a malleable physical form. In FG3, art therapy group member, Eduard makes a comparison between psychotherapy and art therapy, observing that psychotherapy can feel a little invasive sometimes. In contrast, in the following excerpt, Eduard constructs a possible reason for talking in art therapy feeling "more natural", given that the process of drawing makes you single out one aspect. This creates a starting point for the construction of a personal narrative; the action of making organises and helps the person reflect before putting experience into words.

Eduard: [Art therapy] allows you to open up (.) things you think start coming out more naturally because (.) when you draw (.) you concentrate on one particular aspect, maybe you forget a little about the rest [...].

Salvador, in the same focus group talks about the art therapy group helping him feel "mentally much better" and "more open to more possibilities". Here the group is constituted as an opportunity to relate to others, to see commonalities and avoid the pull towards isolation.

Salvador: [....] You would give your self a shell and you would shut yourself in there, you would retreat like a snail (.) and art therapy allows you to understand people, that you are not the only one (.) there are others that are like you, that go through the same problems and the same ailments and the same beliefs and the

Language and Psychoanalysis, 2019, 8 (1), 30-68. 
same difficulties and they make you feel a little more free, a little more (.) more er more more, better (.) mentally you feel much better. More open to more possibilities, because it changes the way you see life."

In FG1, the professional team group, the video elicited discussion of self-expression as a way of dealing with the diagnosis, while in FG2, the family member group, it elicited a dialogue about feeling fulfilled.

Miquel: Hell, the main thing is he accepts what he has got /

Maria Luz: Yes, um.

Miquel: Eh? He even accepts that he is altering, he is changing, because the difficulty, I have not achieved it, is that she accepts it, because each time she can't do something because she drops it, she does not have the strength to work.

Miquel interprets from the video that the former group member it features has accepted Parkinson's and his situation. In this extract Miquel compares this notion and even mixes it ambiguously with his own narration of his wife's experience. He says he has not achieved this acceptance, suggesting acceptance is a goal and either that he, as the informal caregiver, is somehow responsible for the process, or that he himself has not accepted his wife's diagnosis. The dialogue between the caregivers develops with them debating acceptance.

Amelia, a family member in FG2, appropriates an idea from the video narrative to share with her husband:

Amelia: This idea I, I don't know, to talk to Julio, because we had not focused on that, [....] to say well m:: everything starts one way and we end up another way, well we are beginning a new opportunity because it is a different life, but one we can also enjoy.

In the FG4, the art therapist group, there was an interesting development related to ideas about art therapy for different client groups. They questioned the categorization of groups according to stages of the illness and the possibilities of grouping clients in different ways other than focusing on pathology.

Elisabet: [...] for me it was not so important what it was they were suffering, it was more about what they needed and what they were looking for, right?

Marianne: [....] for me it has been important to be there for the person, not the Parkinson's sufferer but an intervention directed towards the person (.) right? And towards their potential.

Both art therapists describe a shift in focus, putting the person before the illness. This shift is subtle but significant, moving away from labelling and categorisation to a collective in which difference can co-exist. 


\section{Artwork as Legacy}

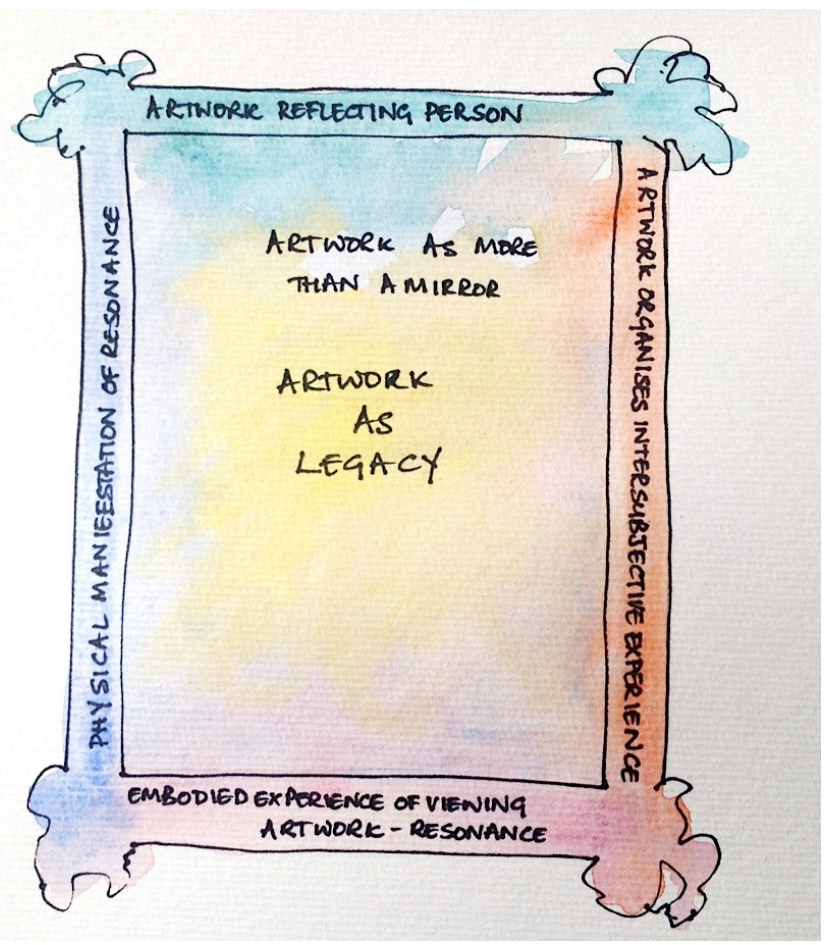

\section{Figure 6}

Thematic network 'artwork as legacy'

The theme 'artwork as legacy' (see figure 6) is derived from the artwork reflecting aspects of the person or their situation, which was identified in all four focus groups. However, as I will later discuss, the artwork is not a simple flat mirror of its maker. The function of the group as multiple mirrors was particularly emphasised by the art therapists (FG4) and the professionals (FG1) from the multidisciplinary team.

Marianne: [...] in the group we are multiple mirrors, right? So we reflect ourselves in one another and and:: we can feel comfort too, right? From from the point of view that (.) that here I can relax as well with what I have and I do not have to (.) keep up appearances, right?

In Marianne's discourse there is an allusion to psychodynamic processes of projection and identification between group members. However she directly includes herself using the pronouns "we" and "I" when she is narrating feelings conjured in the group experience. Here she portrays a positive experience of universality (Yalom \& Leszcz, 2005) and introduces the idea of revealing a "true" self, from behind a facade that the person maintains outside the group. This constitutes the art therapy group as a safe place, which facilitates self-revelation. Inma (FG1) highlighted the potential in the group to influence the actual construction of the artwork and what is reflected back to the creator: 
Inma: In a group process there is an interaction and reciprocal influence in the constructive process of the artwork, widening the vision of the individual and at the same time as functioning as their mirror.

Salvador (FG3) refers to the artwork as both instigator and receiver of the individual and group material. His words could be understood as the active role of the artwork either in making the person be sincere with the group or in making the content (doubts, fears, shadows) visible to the group. Salvador described:

Salvador: It [art therapy] opens up your spirit (.) it makes you be sincere with your companions (.) sin-sincere with them about your doubts, your fears, your shadows

(.) and and esc-they are reflected in an object that can be a figure, or a drawing

(.) a watercolour or a painting or as [xxxxx] of these.

\section{Physical Transformation-As a Relational Aesthetic Experience}

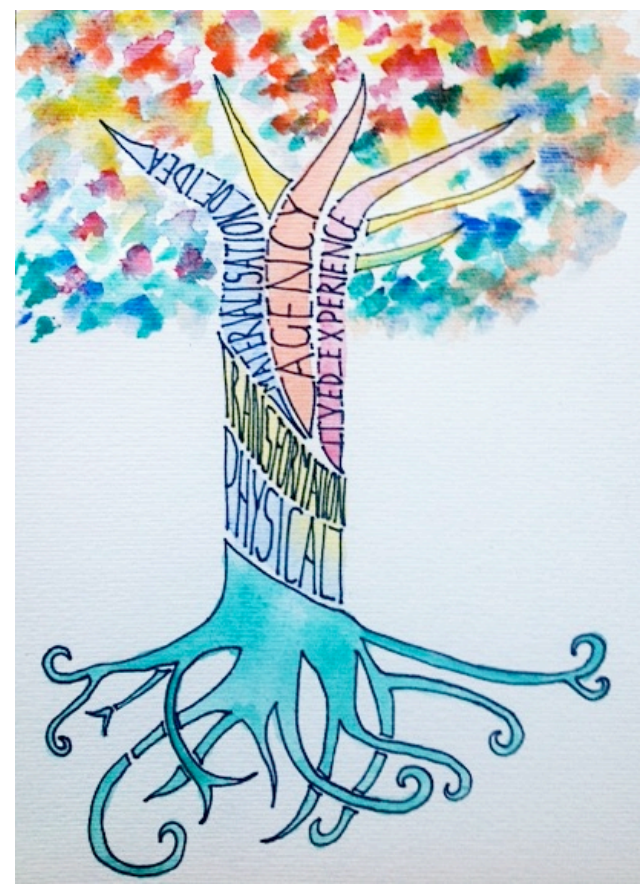

\section{Figure 7}

Thematic network 'physical transformation - as a relational aesthetic experience'

The final theme 'physical transformation' describes the aesthetic experience of creating an artwork in a group in an art therapeutic setting. The artwork becomes a meaning-generator which performs many functions. These include offering visual metaphors, holding the projection of difficult emotions and triggering personal memories. Creating holds the potential for taking an idea and giving it a tangible form. The materialisation of this idea is a transformation and the result is external, concrete and more often than not quite different from the original idea, heavily

Language and Psychoanalysis, 2019, 8 (1), 30-68. 
influenced by the context within which it is made. Inma, FG1, describes this process of transformation:

Inma: I also consider it to be a discipline that without judging the person's production [artwork] it favours a change in their outlook, externalising and transforming difficult aspects or problems into creations... I mean, it can help a person materialise the changes on a tangible level, not just in thought.

The creative process is not an idyllic experience; both tangible and non-tangible, it is a process which involves chaos and frustration as well as gratification. The creative process offers group participants an opportunity to observe themselves in action and how they deal with the feelings and emotions the process elicits. Inés, in FG1, described such a learning experience as transferrable to dealing with situations in everyday life. The professionals in FG1 emphasised the potential for learning from observing other group members. Creating and reflecting on the resulting artwork in a group psychotherapeutic environment offers the opportunity to observe, reflect on and learn from other group members' viewpoints and life experiences.

The creator leads in the creative process. For people whose autonomy has been limited as can happen to those affected by Parkinson, the creative process offers them a sense of agency over what they are doing.

\section{Discussion}

I conclude by reflecting on each of the themes that emerged through the thematic analysis and relating them to relevant literature.

\section{Theme 1 - Self-construction}

When each focus group was asked to define art therapy in their own words and the verb "express oneself" was repeated in all four focus groups, using a psychological discourse to define a process in which the person (re)discovers parts of themselves. They described discovering abilities, feelings, motivation to do things or the artwork becoming a mirror which reflects parts of the artist. Based on the idea that through language we construct ourselves and our experiences (Burr, 2002), I deliberately substituted the word 'expression' for 'construction', questioning an underlying notion that a person has a fixed sense of 'self' waiting to be expressed. I believe we are continually self-constructing and thus art therapy groups are a potential space for these processes to be explored and reflected on. However, I acknowledge this might sit awkwardly with the psychological discourse of a true internal self, waiting to be discovered below the layers of social duties, that seemed to be present in the research participant's discussion.

The focus on action and developing an awareness of emotional responses in the body that occur while making the artwork in the excerpts relates to Haraway's (1988) feminist thinking, looking to the body as an agent in meaning production. Haraway suggests a theoretical category in feminist theory "the apparatus of bodily production" (p. 595) which is dedicated to "understanding the generation - the actual production and reproduction - of bodies and other objects of value in scientific knowledge projects." (p. 595). Tamara, the social worker in FG1, suggested that art therapy works on two levels, individual and group, the individual level she describes as:

Language and Psychoanalysis, 2019, 8 (1), 30-68. 
Tamara: The individual works with themself when they express something and when (.) well the moment the feeling that they are living like (.) like expressing it not with words but with facts.

Tamara views the production of an artwork as a 'factual' representation of emotions, implying that the artwork is a 'more faithful' representation than words. Haraway (1988) invites us to consider "the object of knowledge as an active, meaninggenerating part of apparatus of bodily production" (p.595). In the case of art therapy this conceptualises the art object not as a source of truer knowledge, but acknowledges its presence as an independent actor, active in the process of meaning production (see the second sub-theme represented by the first finger in Figure 2). In other words, an artwork does not merely passively nor neutrally, transmit the intentions of the artist.

Intuitive action in the creative process can lead to the externalisation of unconscious material, which then can be seen by the creator. From this point the creator becomes more in tune with his emotions and bodily expressions leading to affect consciousness as a therapeutic outcome in art therapy (Holmqvist et al., 2017).

Dealing with the unconscious or unknown is threatening, taking people out of their comfort zone. Art was perceived to be threatening for people who do not have that "special sensibility", described in FG1. As humans we all have a personal history with art, a bank of positive and negative experiences, from school and home life. It only takes one negative experience to break the enjoyment of doing art as a child and from that point instilling the belief that you are not 'artistic'. Returning to art materials as adults can elicit these memories and, if not addressed, asking someone to express themselves without giving any kind of direction could cause high levels of anxiety (Huet, 2016). So in theory telling someone to "let go" may seem like the key to engage with art therapy, but in practice it can be an obstacle.

Holmqvist, Roxberg, Larsson \& Lundqvist-Persson (2017) explore the ways inner change may appear in art therapy, and their theme "Creating comprised playful experimentation and exploration" (p. 48, italics in the original) seems pertinent to the element of discovery and surprise in self-construction. The client opens up through the creative process, becoming more comfortable and confident with the art materials and able to play freely. The authors relate the playful experimentation to the theory of Winnicott (1971/2005) postulating the importance of creativity for human development. Here I would like to emphasise the word process in relation to artmaking, it involves the action of using art materials, getting to know the art therapy space and being in the moment of exploration, gradually allowing the end result to be a surprise as opposed to something that may not meet with the artist's initial expectations.

The participants' emphasis on the need to let go leading to feeling free in group art therapy may suggest feeling constricted in other areas of life. It could also refer to the experience of fully engaging with and enjoying the creative process in the form of transcendence (Gerber et al., 2012). "Pleasure and play" is theorised by Gabel \& Robb (2017) to be a particular therapeutic factor in group art therapy, describing the sensory enjoyment of using and mastering art materials through play.

Language and Psychoanalysis, 2019, 8 (1), 30-68. 
The distinction that the art therapist Marisol, FG4, made between the emphasis on motivation in art therapy and the rehabilitation focus of other therapies conforms with what the literature on art therapy and Parkinson's, which suggests art as a source of purposeful motivation, about the person not the illness. Art enables a focus on ability instead of a person's limitations (Cossio, 2002; Tingey, 2002, 2004; Wadeson, 2003). I would go further and suggest that this change of focus happens not as a simple change of attitude but through bodily experience.

Reeve (2002) describes the psycho-emotional dimensions of disablism as related to the body, arguing that the medical model uses the clinical gaze to identify pathology, how the body deviates from the norm, which in turn constitutes the subject as "patient". This gaze exercises power over people with disabilities in everyday life, lending influence to stereotyping and social prejudice, inducing shame, feelings of vulnerability and invalidation in the recipient. Reeve's ideas are based on Foucault's concept of power, the 'gaze' being a technology of power. She uses Foucault's understanding of subjectivity "the manner in which identity emerges from the interactions of discourses, ideologies and institutional practices rather than being a product of the self-governing conscious self" (Reeve, 2002, p. 503) and how technologies of the self describe ways of self-transformation implying an active as opposed to passive subject. Through technologies of self a person can challenge any stereotypes of their disability they have internalised. Keeling and Bermudez (2006) report client experience of regaining a feeling of agency over their problems through the process of making and reflecting on an art object. The study described a directive externalisation approach as a tool in narrative therapy. In contrast, in the current study the creative process is considered as much more nuanced and not simply an externalisation technique. The group member's process of (re)discovering positive active capacities through their creative-process is here is motivational and opens the grounds for Reeve's self-realisations and transformations (see the little finger in Figure 2, a guiding finger that I imagine to be reached through the other fingers).

\section{Theme 2 - Material Action}

The second theme 'material action' is very much linked to the first, building on 'body as a meaning generator'. The visual metaphor of a bird in flight is my attempt to show the link between action and creative freedom. The wings contain the sub-themes or components the focus group participants explored in relation to the act of engaging with the art materials. The role of embodied action involved in the art process significantly differentiates group art psychotherapy from verbal group psychotherapies (Holmqvist et al., 2017). At the CPA the accompanying group conductor uses a non-directive approach, encouraging free exploration of the art materials without imposing a specific theme or direction on the group (McNeilly, 1983, 2006). Part of the role of the art therapist/conductor is to draw the group participant's attention to the process of art-making, facilitating an understanding of the creative process as a mode of self-expression with the potential to create new relationships and ways of being (Case \& Dalley, 2006). In this section I am going to address two issues related to the use of art materials: the potential of the creative process as embodied action and the difficulty of engaging in 'artistic' endeavours due to an elitist view of art. 
The here and now in material action I have spoken about to clients as an art therapist. Through verbal language we construct a vision of ourselves that can be very different from the way we react to stimulus in our environment. The creative process allows us to observe our own reactions and see ourselves from a different perspective. However, we first have to tune into the possibility of observation of oneself in action. Elisabet (art therapist FG4) emphasised the importance of the client having access to a wide range of materials and shared her thoughts about broadening the spectrum beyond those that are classic art materials by including materials specifically related to a new client's background, not being bound by set ideas of the 'artistic'.

Moon (2011) challenges the missed potential in the art therapy world of engaging more with the contemporary art scene, observing that the boundaries of what is art and what is not are now merging. Moon postulates that art tendencies are no more than direct reflections of social tendencies, deconstructing the common belief that art requires talent to produce and a special intellect to understand it. Often the success of art therapy can be seen to pivot on the quality of the art materials provided. If they are of good quality the person will have the potential to do things they would not be capable of with materials of lesser quality. Such materials may, however, be felt as threatening. Alternatively, if perceived as poor quality the person might be restricted by a lack of, or child-like, quality, associated with the materials. Either way the materials may be positioned as having an active role in the way a person responds to art therapy.

I have battled with my own fragile conviction that art as a medium can be made accessible to people with no artistic experience, what's more, bring them therapeutic benefits based on the discourses of art and therapy, both reinforcing contradictory connotations: art being for children or an elite group of gifted adults; therapy remaining deeply embedded in psychological discourses which lead it to be stigmatised as a service for the mentally unstable or sick who can not cope alone (Goffman, 1963/1990; Strand \& Waller, 2010).

Spaniol (2005) challenges these discourses through a participatory art research project advocating art-making as a common language to share ideas between disparate groups as equals. Art allowed the participants in this study (group members and art therapists) to challenge discourses related to mental health and art therapy services creating new terms that reflected their interconnection instead of binary positions of service user and professional. In order to make use of a new creative language, the language first needs to be made accessible. In group art therapy this is where both the art therapist and the group itself play key roles. In FG2 with family members, four of five participants made references to their spouse not being creative or artistic. Two members of the former patient focus group also referred to themselves as not being creative or imaginative but still advocated benefits.

For Butler (1990/2006), subjectivity is an act of doing, a verb in this sense it is action that produces subject recognition not the subject doing the action. This links to Haraway's theory of body as an agent (1988), it is bodily performance or action that generates insights. This material action allows the body to become a meaning generator and the wings are filled with the sub-themes that reflect challenges in this process. I saw the air movement around the bird, generated by the flapping wings, as being creativity and synonymous to flexibility in thought and action.

Language and Psychoanalysis, 2019, 8 (1), 30-68.

http://dx.doi.org/10.7565/landp.v8i1.1591 


\section{Theme 3 - An Aesthetic Group Movement}

By organising the themes separately I risked creating the illusion of finite separate categories. On the contrary, I want to emphasise the constructive nature of interdependent themes with permeable boundaries and their inseparability from an experience as a whole (Brinkmann, 2014) and I refer the reader back to Figure 1 which shows how the themes related to each other in linear form. As I made the illustrations of each global thematic network I also found myself linking the subthemes from different main themes. In Figure 4, an aesthetic group movement is represented by a circle which contains the group experience while the sub-themes flow around it, leading into each other. In each illustrations I found myself instinctively connecting all the images using the same colour for sub-themes that seemed to interlink from each main theme. For example, blue in Figure 2 for 'physically creating', in Figure 3 for the act of creating or 'creativity' (the moving air around the bird) and in Figure 4 in relation to 'total freedom' a feeling experienced through the creative act. 'An aesthetic group movement' conveys the importance of the group experience as key for art therapy.

Flow as an experience of the ideal level of attention and engagement in an activity such as art-making has been connected to creativity and well-being, making it an area of interest for art therapy research (Chilton, 2013). Chilton summarises the characteristics of flow as being manifested by:

(a) intense and focused concentration, (b) merger of action and awareness, (c) loss of self-consciousness, (d) increased sense of control, (e) changed phenomenological experience of time and a sense of speeding up time in particular, and (f) autotelic experience, which is the sense that the activity is intrinsically rewarding or worthwhile in its own right. (2013, p. 64)

We can speculate that Enric's (former art therapy group member FG3) feeling of freedom was a result of flow and the group being a key component for generating that flow. The emphasis on the group as central reinforced the idea that it is not an experience that can be forced but one process naturally leads to the next. This component could be a manifestation of what Foulkes (1971) described as group resonance, an empathic group response to nonverbal subconscious communication that becomes active in the interpersonal space. The process further relates to the scapegoating of difficult experiences in the artwork (Schaverien, 1999), which they can then face together.

Making a creative response whilst listening to the recording of each focus group encounter was very helpful as away of dealing with the contrast between the flatness of the transcriptions and the multilayering in the experience of the focus group, especially with the former art therapy group members (FG3).

Language and Psychoanalysis, 2019, 8 (1), 30-68. 


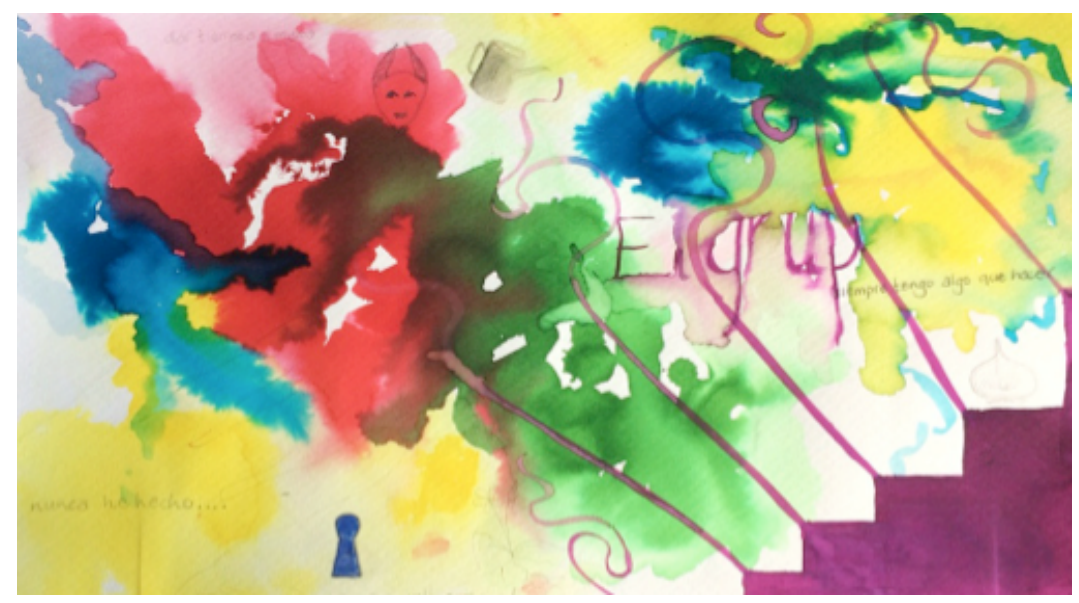

Figure 8

Researcher creative response to FG3

The material I chose was watercolour ink, which I had fun applying because it is quite unruly and very vibrant. This is coherent with my experience of conducting this particular focus group. Looking at the image I still see the intensity of my personal experience: of my worrying about their physical vulnerability; worrying about the discussion topic (and perhaps even art therapy itself) being a triviality in comparison to their difficult life situations; a contrasting strength and vibrancy that developed in the jovial group interaction. Palpable feelings of passion, rage, vulnerability and masculine sexuality were all on the cusp of breaking through the harsh reality of the progression of Parkinson's, some members being markedly more affected by the condition than when they last saw each other.

\section{Theme 4 - New perspectives}

The process of homing in on one aspect at a time in the drawing process was key when developing the theme of 'new perspectives' (see Figure 5) leading me to use the visual metaphor of a magnifying glass. Further, its form is similar to the circle in the previous theme, conveying the way the components nourish one another and are not mutually exclusive.

The sense of group and art making in a group were of vital importance to the generation of new perspectives. Group members compared and contrasted experiences coming to understand their individuality as well as nurturing a sense of belonging. Salvador talked of the draw towards social isolation which he was able to overcome with the positive art therapy group experience. Art therapy offers a group retreat where the person finds comfort and strength in universality (Yalom \& Leszcz, 2005), realising his problems are not individual but collective.

The family members emphasised how group art therapy had helped with acceptance. We could question what a person with Parkinson's is being expected to accept? The label of having a Parkinson's diagnosis and the prognosis that they have a progressive incurable illness is accompanied by a change in social position. Defining this change

Language and Psychoanalysis, 2019, 8 (1), 30-68. 
as pathological is accompanied by social stigma. I am not questioning the benefit of using medication to alleviate symptoms but do want to raise awareness of the social stigma the medical discourse brings with it. Change is an intrinsic part of the human condition, however medicine marks change brought on by illness as pathological. Critical psychology (Parker et al., 1995), Disability studies (Goodley, 2011; Reeve, 2002) and Queer theory (Butler, 1990/2006; Clare, 2001), highlight that the medical discourse places the origin of illness in the individual, creating a form of social oppression that lead to chronic illness such as Parkinson's and the visible physical deviation it may cause in the body. This type of change is internalised as a problem to be assumed and dealt with by the individual. Clare (2001) advocates that challenging the belief that deviation or difference is undesirable is the first step toward changing social perspectives. Understanding and accepting difference as part of life offers new perspectives and creative ways of dealing with an uncertain future.

\section{Theme 5 - Artwork as Legacy}

Traditionally the images created in psychodynamic art therapy have been considered to reflect the inner world of the client; however, although similar to simple mirror reflections these images are also quite distinct from them (Schaverien, 1995). The mirror as metaphor has also been used widely in group analysis (Nitsun, 1996; Pines, 1984). Schermer (2010) critiques the mirror as a metaphor for human experience in psychoanalysis and group analysis, first exploring what a mirror is and does. Schermer highlights that a mirror is a real surface that reflects a virtual reality and allows the observer to see themselves outside of themselves in the virtual space. However he contends that, unlike the photograph, film or painting, a mirror is limited to providing an immediate, simultaneous reflection of the observer: "A mirror has no memory or representational-interpretive capability" (Schermer, 2010, p. 217), meaning that as a metaphor it does not portray the complexity of the experience in social interactions. He does, however, suggest that a painting can do this. Thinking in these terms has led me to propose the metaphor of the artwork as 'legacy', "something that is a part of your history or that remains from an earlier time" (Cambridge English Dictionary, 2018).

The emotional embodied experience of viewing a painting has parallels with the group-analytic concept of resonance (Foulkes, 1971). McNeilly (1984) discusses resonance in relation to art psychotherapy groups and the potential for artwork to express the collective unconscious in the manifestation of collective imagery spontaneously occurring without allying to intellectualisation as often happens with words, however he does not explore how the artwork might do this. In FG3 (former group members) they did not use the metaphor of mirror, however they did describe the inter-subjective relations in terms equating to resonance. Eduard's description of art therapy as ganzúa earlier in this paper led the former patient group to construct the experience of feeling free, which related to a group resonance in which the artwork was key. The artwork became a physical manifestation of resonance.

The therapeutic outcome of bringing the creation of artwork into a group therapy setting seem to come through in Salvador's discourse in psychological terms as broadening the potential for inter-subjective learning through identification, projection and individuation (Atwood \& Stolorow, 1984). These processes are worked through with the art objects and the other group members. The physicality of

Language and Psychoanalysis, 2019, 8 (1), 30-68. 
the work with art materials and the art production offers a sensory experience that holds the events of the session in a way that is not possible with words alone. For a person with Parkinson's not being able to concentrate is a common complaint, art therapy can offer them a way to organise their experiences in a tangible way that can then be complemented by words. I will explore this idea further in the following section.

A family member of one of the four research participants who died during this study told me that they had chosen a picture from his folder to frame and hang in her home another form of legacy. This relates to the resonance present in the artwork, it is a physical object unique to the artist and a manifestation of the slice of time when they made it. The content of the resonance for the family member is likely to be different from the resonance experienced by the group. However, the artwork is similarly imbued with attributes of the maker as well as being the receiver of the feelings the observer attaches symbolically to the object. In this way attributes of self and other coexist in the artwork. Together these come to represent the aspects of the intersubjective relationship between artist and observer. I want to highlight two uses of artwork as legacy, one being at the service of the creator, becoming a testimony of their experience; and the second artwork as legacy for those the artist leaves behind. Artwork as legacy in both senses has been observed in other studies, especially related to art therapy for older people (Johnson \& Sullivan-Marx, 2006) and people affected by a terminal condition (Carr, 2014).

\section{Theme 6 - Physical Transformation as a Relational Aesthetic Experience}

The psychologist, Inma's words excited me as she explicitly keyed into an idea that, as an art therapist, has helped me counterbalance the feeling of hopelessness at not being able to take the illness away from people with Parkinson's. The physical transformation of a feeling or a thought offers the person some agency over a situation they can feel dominated by (Keeling \& Bermudez, 2006). I propose that the gratification to be found in the creative process of art therapy lies in the opportunity to face an issue head on, create a little distance to see it as separate and then create something new out of that same issue. Reynolds and Prior (2003) found creating art to fulfil the role of "increasing control and choice - challenging victim status" (p. 788) for women living with disabling chronic illness. In the thematic illustration agency (Figure 7) is the central ramification and most prominent. The physical transformation in art seemed to be a catalyst for personal transformation.

These ideas correspond with the concept of 'relational aesthetics' describing "the overlapping triangular relationship between group members, artworks, and leaders in which the art serves as a medium for visual/nonverbal and verbal feedback" (Gabel \& Robb, 2017, p. 129). Relational aesthetics is one of five therapeutic factors the authors deem as unique to group art therapy. Combining 'relational' and 'aesthetic' captures a central component of group art therapy; the opportunity to become aware of embodied intersubjective experience of oneself in relationship with an other (art materials, group situation and group members). This is learning from experience at its essence, words become superfluous. 
The tree in figure 7 helped me imagine physical transformation as organic growth that is hard to perceive when the person is in the process of making but on reflection can reveal a multifaceted experience. In this illustration the green in the roots was inspired by the green in the first global theme which I related to 'letting go-feeling free' (see Figure 2). This was deemed essential for engaging in art-making. Looking at my drawing of the tree the black line delineates the bottom section containing the green colour, I find myself associating this with the difficulty of letting go, a reminder that it is not an automatic process for everyone.

\section{Conclusion, Limitations and Future Studies}

The first three main themes: 'self-construction', 'material action' and 'an aesthetic group movement' create a definition of group art therapy for people with Parkinson's. The art-making process becomes a tangible means of expression involving discovery and surprise and the resulting artwork becoming an actor helping the group members to understand their experience. The three themes are interdependent and remain consistent with what has been previously reflected in the literature on group art therapy or art as therapy for people with Parkinson's (Cossio, 2002; Tingey, 2002, 2004; Wadeson, 2003).

The art therapists at Catalan Parkinson's Association, including myself, all trained on the same programme and the basic principles for the model of art therapy they offered comes from a non-directive psychodynamic approach to group art therapy. This approach is historically tied to an individualistic psychological discourse aiming to uncover deep unconscious meaning (Hogan, 2017). This component in the practice under-study here, although latent for the family members, was not valued as much as the relational aspects of the experience between the person, the art materials and the group. By the end of my doctoral journey I found myself aligning with critical psychology's refusal of a defined psychological model of the person (Parker, 2013) opening up to social psychology (Burr, 2002) and community psychology (Prilleltensky, 2001) perspectives which shift the focus from the individual psyche to wider social and collective constructs of the individual. I was thus exploring how art therapy practice at this research site had come to be understood and its function within this community of people affected by Parkinson's.

My position as artist-therapist-researcher put the artistic component at the forefront and I found myself looking for therapeutic factors that could be considered unique to art therapy. Themes four to six are directly linked to features of group art therapy that were prominent for this client group. Theme four the generation of 'new perspectives' refers to specific ways that physically creating, combined with self- and groupreflection, establishes a distance to allow the ordering and exploration of personal experience, as well as issues related to difference to be addressed. Theme five 'artwork as legacy' described the role of the artwork as more than a simple reflection of aspects of the individual person, embodying group resonance and intersubjective learning. For practice this encourages a focus on relational aspects of making and viewing the artwork, acknowledging the active role of the artwork in shaping the group members' experience. The sixth 'physical transformation as a relational aesthetic experience' emphasises the embodied learning experience in art therapy, from the physical shaping of an idea to regaining some agency over the person with Parkinson's situation through the process of symbolic representation, physical

Language and Psychoanalysis, 2019, 8 (1), 30-68.

http://dx.doi.org/10.7565/landp.v8i1.1591 
manipulation and shared non-verbal group resonance. The action-based learning gained through using the art-making process seemed to offer a tangible experience accompanied by and providing containment for a range of emotions for the participants. These findings can contribute to theories of body and affect conveying the potential for the conceptualisation of relational learning processes in which the body and interaction with material reality are the focus.

My dual position as researcher and former art-therapist at the CPA could be considered a limitation encouraging the research participants to only focus on the positive aspects of the therapeutic modality. I made a point of asking about negative experiences but this was met with much resistance especially in the former patient focus group. Having a familiar relationship with the research patients did however promote a relaxed atmosphere and favoured in-depth exploration of their experience with art therapy. In the focus group with family members there were some doubts and insecurity about the efficacy of art therapy, but the focus group discussion helped clarify the purpose of the art therapy groups between the family members in the exchange.

The themes describe the basis for a model of group art therapy for people with Parkinson's which focuses on a therapeutic space for exploring relational aspects of experience between the group members and their artwork, instead of breaking down the approach into individual objectives directed towards the alleviation of specific motor and non-motor symptoms. The focus groups unanimously positioned the roles of the group and art-making as interwoven and central to the therapeutic process, contrary to suggestions from earlier research that individual art therapy might be more useful to people with Parkinson's than a group approach (Strand \& Waller, 2010).

The move away from an emphasis on symptom alleviation challenges traditional cognitive therapeutic approaches to go beyond the individual to consider relational aspects of experience which are embedded in a social context. The focus on the person affected as a whole and their experience as situated in a social context is an important contribution of this study to the field of Parkinson's and people affected by other long-term life changing conditions.

The analysis has highlighted other factors needed to allow people affected by Parkinson's to engage fully in group art therapy. Personal believes of a lack of creative ability (Huet, 2016) can be a serious obstacle, creating resistance to the idea of art-making and preventing full engagement. Group art therapy also challenges social preconceptions of art as being a product of special talent. Art is a new unpredictable language, and the group forms important support for learning and navigating the space together. Relational aesthetics (Gabel \& Robb, 2017) was a particularly important therapeutic factor. It conceptualises the positive impact of the creative activity and presence of the artwork on group cohesion which was a prominent feature evident in this study and warrants further research.

The focus group method was successful in the present study. All four focus groups reported their positive interpersonal learning experience through comparing and contrasting ideas and experiences facilitated. For the multidisciplinary team it reinforced the importance of communication between team members, the desire for interdisciplinary exchanges and the possibility of trying art therapy workshops as a

Language and Psychoanalysis, 2019, 8 (1), 30-68.

http://dx.doi.org/10.7565/landp.v8i1.1591 
team-building exercise. The family caregiver participants appreciated having a space for exchange that allowed them to discuss and understand art therapy as an approach for this client group in addition to sharing personal experiences. The art therapists enjoyed a space to think critically about their own practice. The former art therapy group members enjoyed the opportunity to reconnect with each other and it revalidated their experience in art therapy and what aspects remained significant to them. The focus group encounter had direct impact on the participants, highlighting how the process of carrying out research modifies reality at the research site (Lather, 1986) meaning the benefit for those involved should be carefully scrutinised.

It could be considered a limitation that the focus groups were one off encounters and a series of follow-up sessions could offer a more in-depth engagement with the research topic. In the current study the present analysis of the focus group data was triangulated with individual interviews and an analysis of transcripts and images from nine group art therapy sessions. A possibility for further study could be to create artbased workshops with a group discussion to engage all research participants with the direct experience of art-making. Exploring experiential aspects would further understanding of art therapy principles in ways that are not reached on a purely intellectual level.

The present research has led to establishing contact between group art therapy programmes for people with Parkinson's across the world. An image exchange and series of exhibitions began in 2016 between "Painting with Parkinson's" Canberra, Australia and the programme under study here. This has led to more groups being set up and offers the potential for further empirical comparative studies to examine the impact of intersectional aspects such as culture, class and gender, both on the experience of Parkinson's and group art therapy practice. To conclude, the results of this study may not be generalisable in positivist terms, however there is great potential for extrapolating the findings and exploring them in relation to other chronic lifechanging conditions.

\section{References}

Attride-Stirling, J. (2001). Thematic networks: an analytic tool for qualitative research. Qualitative Research, 1, 385-405.

Atwood, G., \& Stolorow, R. (1984) Structures of subjectivity: Explorations in psychoanalytic phenomenology. New Jersey, NJ: Analytic Press

Barichella, M., Cereda, E., Cassani, E., Pinelli, G., Iorio, L., Ferri, V., \& Pezzoli, G. (2017). Dietary habits and neurological features of Parkinson's disease patients: Implications for practice. Clinical Nutrition, 36, 1054-1061.

Bloem, B. R., de Vries, N. M., \& Ebersbach, G. (2015). Nonpharmacological treatments for patients with Parkinson's disease. Movement Disorders, 30, 1504-1520.

Bradt, J., \& Goodill, S. (2013). Creative arts therapies defined: comment on "effects of creative arts therapies on psychological symptoms and quality of life in patients with cancer". JAMA Internal Medicine, 173, 969-969.

Braun, V., \& Clarke, V. (2006). Using thematic analysis in psychology. Qualitative Research in Psychology, 3, 77-101.

Burman, E., \& Parker, I. (Eds.) (2016). Discourse analytic research: repertoires and readings of texts in action. London, $\mathrm{UK}$ : Routledge

Language and Psychoanalysis, 2019, 8 (1), 30-68.

http://dx.doi.org/10.7565/landp.v8i1.1591 
Burr, V. (2002). The person in social psychology. New York, NY: Taylor and Francis

Butler, J. (2006). Gender trouble. New York, NY: Routledge. (Original work published in 1990)

Cambridge English Dictionary. (2018). Retrieved from https:/dictionary.cambridge.org/dictionary/english/

Carr, S. M. D. (2014). Revisioning self-identity: The role of portraits, neuroscience and the art therapist's "third hand". International Journal of Art Therapy, 19, 54-70.

Canesi, M., Rusconi, M. L., Isaias, I. U., \& Pezzoli, G. (2012). Artistic productivity and creative thinking in Parkinson's disease. European Journal of Neurology: The Official Journal of the European Federation of Neurological Societies, 19, 468-472.

Case, C., \& Dalley, T. (2006). The Handbook of art therapy. London, UK: Routledge.

Chatterjee, A., Hamilton, R. H., \& Amorapanth, P. X. (2006). Art produced by a patient with Parkinson's disease. Behavioural Neurology, 17, 105-108.

Chilton, G. (2013). Art therapy and flow: A review of the literature and applications. Art Therapy, 30, 64-70.

Clare, E. (2001). Stolen bodies, reclaimed bodies: Disability and queerness. Public Culture, 13, 359-365.

CPA [Catalan Parkinson's Association]. (n.d.) La Malatia de Parkinson. Assocació Catalana per al Parkinson. Retrieved from http://www.catparkinson.org/parkinson

Cossio, A. (2002). Art therapy in the treatment of chronic invalidating conditions: from Parkinson's to Alzheimer's. In D. Waller (Ed.), Arts therapies and progressive illness: nameless dread (pp.47-55). New York, NY: BrunnerRoutledge

Elkis-Abuhoff, D. L., Goldblatt, R. B., Gaydos, M., Ma, S. C., \& Corrato, S. (2013). Effects of clay manipulation on somatic dysfunction and emotional distress in patients with Parkinson's disease. Journal of American Art Therapy, (February), $37-41$.

Ellingson, L. L. (2006). Embodied knowledge: Writing researchers' bodies into qualitative health research. Qualitative Health Research. 16, 298-310.

Feen-Calligan, H. (2008). How do we care for people? Introducing a special issue on art therapy in palliative care. Art Therapy, 25, 106-107.

Foulkes, S. H. (1971). Access to unconscious processes in the group analytic group. Group Analysis, 4, 4-14.

Foulkes, S. H. (1986). Group analytic psychotherapy: Method and principles. London, UK: Karnac Books. (Original work published in 1975)

Gabel, A., \& Robb, M. (2017). (Re)considering psychological constructs: A thematic synthesis defining five therapeutic factors in group art therapy. Arts in Psychotherapy. 55 (2017), 126-135.

Gerber, N., Templeton, E., \& Chilton, G. (2012). Art-based research as a pedagogical approach to studying intersubjectivity in the creative arts therapies. $J A A H$ Intellect Limited Journal of Applied Arts \& Health, 3, 39-48.

Goodley, D. (1999). Disability research and the "researcher template": Reflections on grounded subjectivity in ethnographic research. Qualitative inquiry, 5, 24-46.

Goodley, D. (2005). Empowerment, self-advocacy and resilience. Journal of Intellectual Disabilities, 9, 333-343.

Goodley, D. (2001). "Learning difficulties", the social model of disability and impairment: Challenging epistemologies. Disability \& Society, 16, 207-231.

Language and Psychoanalysis, 2019, 8 (1), 30-68.

http://dx.doi.org/10.7565/landp.v8i1.1591 
Goodley, D. (2011). Social psychoanalytic disability studies. Disability \& Society, 26, 715-728.

Goodley, D., \& Lawthom, R. (2005). Epistemological journeys in participatory action research: alliances between community psychology and disability studies. Disability \& Society, 20, 135-151.

Greenstein, A. (2013). Radical inclusive pedagogy: Connecting disability, education and activism. Manchester Metropolitan University.

Greenstein, A. (2014). Today's learning objective is to have a party: playing research with students in a secondary school special needs unit. Journal of research in special educational needs, 14, 71-81.

Habermann, B. (1996). Day-to-day demands of Parkinson's disease. Western Journal of Nursing Research, 18, 397-413.

Haraway, D. (1988). Situated knowledges: The science question in feminism and the privilege of partial perspective. Feminist Studies, 14, 575-599.

Hermanns, M. (2013). The invisible and visible stigmatization of Parkinson's disease. Journal of the American Association of Nurse Practitioners 25 (2013), 563-566.

Hoffmann, N. (2011). Using Art to address cognitive symptoms of Parkinson's disease (M.Sc. Thesis). The Florida State University.

Holmqvist, G., Roxberg, A., Larsson, I., \& Lundqvist-Persson, C. (2017). What art therapists consider to be patient's inner change and how it may appear during art therapy. The Arts in Psychotherapy, 56, 45-52.

Huet, V. (2016, September) Charla sobre Supervisión Unpublished Seminar by la Asociación Española Profesional de Arteterapeutas. Barcelona, Spain.

Inzelberg, R. (2013). The awakening of artistic creativity and Parkinson's disease. Behavioral Neuroscience, 127, 256-261.

Johnson, C. M., \& Sullivan-Marx, E. M. (2006). Art therapy: Using the creative process for healing and hope among African American older adults. Geriatric Nursing, 27, 309-316.

Kang, M.Y., \& Ellis-Hill, C. (2015). How do people live life successfully with Parkinson's disease? Journal of Clinical Nursing, 24, 2314-2322.

Keeling, M. L., \& Bermudez, M. (2006). Externalising problems through art and writing: experience of process and helpfulness. Journal of Marital and Family Therapy, 32, 405-419.

Kulisevsky, J. (2004). Guía terapéutica de la Sociedad Catalana de Neurología. Fundación de La Sociedad Catalana de Neurología, 1-38. Retrieved from http://www.sld.cu/galerias/pdf/sitios/rehabilitacion/enfermedad_de_parkinson.p df

Kulisevsky, J., Pagonabarraga, J., \& Martinez-Corral, M. (2009). Changes in artistic style and behaviour in Parkinson's disease: dopamine and creativity. Journal of Neurology, 256, 816-819.

Malchiodi, C. (1998). The Art therapy sourcebook. New York, NY: Guilford Press

Mannay, D. (2010). Making the familiar strange: can visual research methods render the familiar setting more perceptible? Qualitative Research, 10, 91-111.

McNeilly, G. (1983). Directive and non-directive approaches in art therapy. The Arts in Psychotherapy, 10, 211-219.

McNeilly, G. (1984). Group-analytic art therapy. Group Analysis, XVIII(3), 204-210.

McNeilly, G. (2006). Group analytic art therapy. Philadelphia, PA: Jessica Kingsley Publishers.

Moon C.H. (Ed.) (2011). Materials and media in art therapy: Critical understandings of diverse artistic vocabularies. London, UK: Routledge.

Language and Psychoanalysis, 2019, 8 (1), 30-68.

http://dx.doi.org/10.7565/landp.v8i1.1591 
Nitsun, M. (2006). The group as an object of desire. The group as an object of desire: Exploring sexuality in group therapy. London, UK: Routledge.

Nitsun, M. (1996). The anti-group destructive forces in the group and their creative potential. London, UK: Routledge.

Parker, I., Georgaca, E., Harper, D., McLaughlin, T., \& Stowell-Smith, M. (1995). Deconstructing psychopathology. London, UK: Sage.

Parker, I. (2007). Critical Psychology: What It Is and What It Is Not. Social and Personality Psychology Compass, 1 1-15.

Parker, I. (2013). Qualitative research in psychology discourse analysis : Dimensions of critique in psychology discourse analysis : Dimensions. Qualitative Research in Psychology, 10, 223-239.

Peñas Domingo, E. (2015). El Libro Blanco de Parkinson en España: Aproximación Análisis y Propuesta de Futuro. Federación Española de Parkinson

Powles, W. E. (2007). Reflections on “what is a group ?” International Journal of Group Psychotherapy, 5, 105-114.

Prilleltensky, I. (2001). Value-based praxis in community psychology: Moving toward social justice and social action. American Journal of Community Psychology, 29, 747-778.

Puetz, T. W., Morley, C. a, \& Herring, M. P. (2013). Effects of creative arts therapies on psychological symptoms and quality of life in patients with cancer. JAMA Internal Medicine, 173, 960-969.

Real Academia Española [Tomo I.] (1992) Diccionario de la Lengua Española a-g, Madrid, Spain: Edotorial Espasa Calpe.

Reeve, D. (2002). Negotiating psycho-emotional dimensions of disability and their influence on identity constructions. Disability \& Society, 17, 493-508.

Reynolds, F., \& Prior, S. (2003). “A lifestyle coat-hanger”: A phenomenological study of the meanings of artwork for women coping with chronic illness and disability. Disability and Rehabilitation. 25, 785-794

Schaverien, J. (1999). Art within analysis: scapegoat, transference and transformation. Journal of Analytical Psychology, 44, 479-510.

Schermer, V. L. (2010). Reflections on "reflections on mirroring". Group Analysis, 43, 214-227.

Schofield, S. (2018). Group art therapy for people with Parkinson's, a qualitative study (Doctoral Thesis). Retrieved from https://www.research.manchester.ac.uk/portal/en/theses/group-art-therapy-forpeople-with-parkinsons-a-qualitative-study(1e37dc4c-34cd-4636-b3246f5d563e95f8).html

Shah, S. P., \& Duda, J. E. (2015). Dietary modifications in Parkinson's disease: A neuroprotective intervention? Medical Hypotheses, 8, 1002-1005. http://doi.org/10.1016/j.mehy.2015.08.018

Skaife, S., \& Huet, V. (Eds.). (1998). Art psychotherapy groups: Between pictures and words. London, UK: Routledge.

Springgay, S., Irwin, R. L., \& Kind, S. W. (2005). A/r/tography as living inquiry through art and text. Qualitative Inquiry, 11, 897-912.

Strand, S., \& Waller, D. (2010). The experience of Parkinson's: Words and images through art therapy - a pilot research study. International Journal of Art Therapy, 15, 84-93.

Talwar, S. M. (2010). An intersectional framework for race, class, gender, and sexuality in art therapy. Journal of the American Art Therapy Association, 27, 11-17.

Language and Psychoanalysis, 2019, 8 (1), 30-68.

http://dx.doi.org/10.7565/landp.v8i1.1591 
Tingey, N. (2002). Art therapy as a therapy for Parkinson's. In D. Waller (Ed.) Arts therapies and progressive illness: nameless dread (pp.145-164). New York, NY: Brunner-Routledge

Tingey, N. (2004). Art for Parkinson's. Catalyst, (summer), 4-5.

Wadeson, H. (2003). Art as therapy for Parkinson's disease. Art Therapy, 20, 35-38.

Waller, D. (1993). Group interactive art therapy: Its use in training and treatment. London, UK: Routledge.

Winnicott, D.W (2005) Playing and reality. London, UK: Routledge. (Original work published in 1971)

Wood, M. J. M., Molassiotis, A., \& Payne, S. (2011). What research evidence is there for the use of art therapy in the management of symptoms in adults with cancer? A systematic review. Psycho-Oncology, 20, 135-145

Yalom, I. D., \& Leszcz, M. (2005). Theory and practice of group psychotherapy. New York, NY: Basic Books. 